Document downloaded from:

http://hdl.handle.net/10251/91875

This paper must be cited as:

Jiménez Saez, F.; Zabala Iturriagagoitia, JM.; Zofio, JL. (2013). Who leads research productivity growth? Guidelines for R\&D policy-makers. Scientometrics. 94(1):273-303. doi:10.1007/s11192-012-0763-0

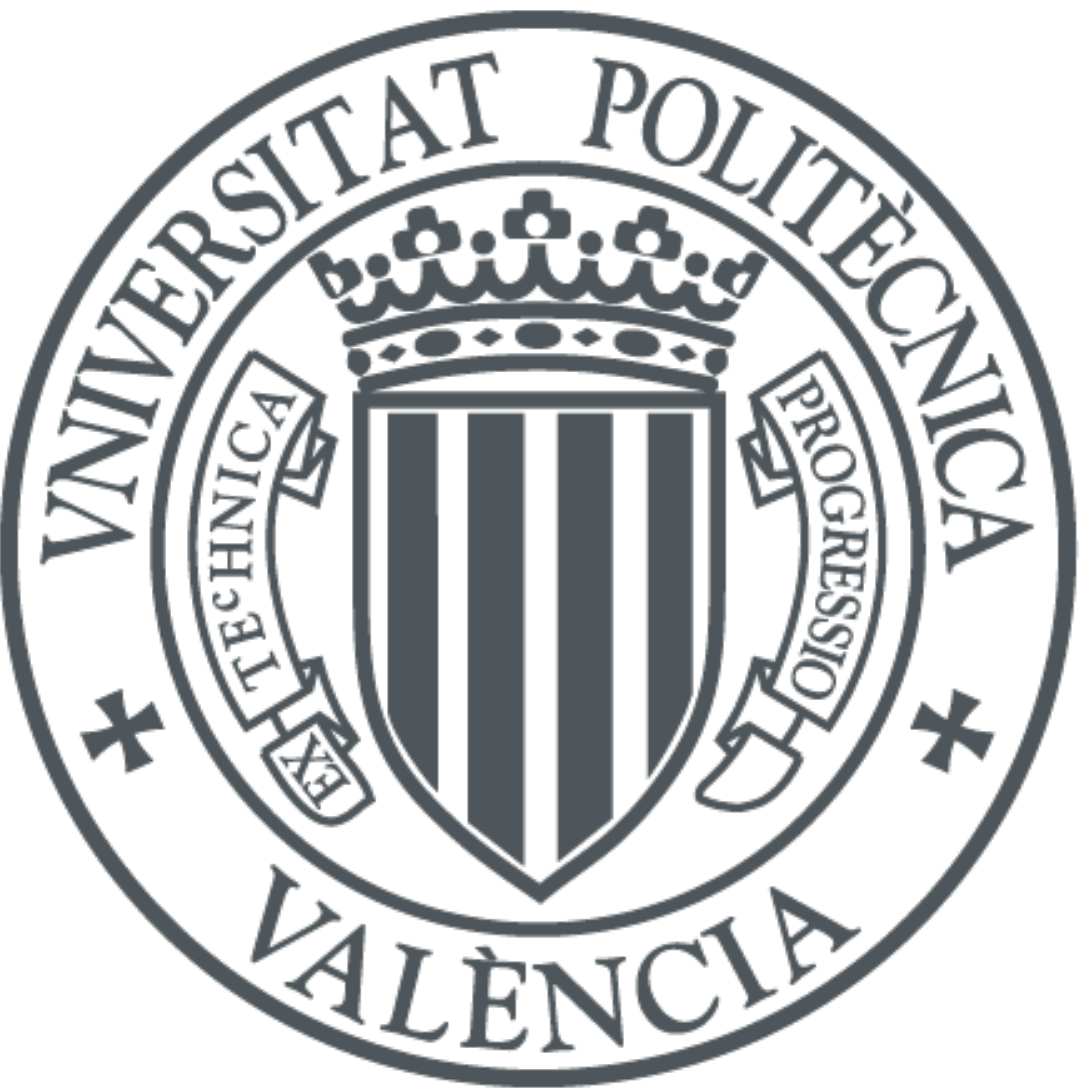

The final publication is available at

http://doi.org/10.1007/s11192-012-0763-0

Copyright Springer-Verlag

Additional Information 


\section{Scientometrics \\ Who leads research productivity growth? Guidelines for R\&D policy-makers --Manuscript Draft--}

\begin{tabular}{|l|}
\hline Manuscript Number: \\
\hline Full Title: \\
\hline Article Type: \\
\hline Keywords: \\
\hline Corresponding Author: \\
\hline Corresponding Author Secondary \\
Information: \\
\hline Corresponding Author's Institution: \\
\hline $\begin{array}{l}\text { Corresponding Author's Secondary } \\
\text { Institution: }\end{array}$ \\
\hline First Author: \\
\hline First Author Secondary Information: \\
\hline Order of Authors: \\
\hline Obstract: \\
\hline
\end{tabular}

\section{Response to Reviewers:}

\section{SCIM1663R1}

Who leads research productivity growth? Guidelines for R\&D policy-makers

Manuscript

Science and technology policy; Policy evaluation; Malmquist productivity index; Data Envelopment Analysis.

Jon Mikel Zabala-Iturriagagoitia, PhD

Lund University

Lund, SWEDEN

Lund University

Fernando Jiménez-Sáez, PhD

Fernando Jiménez-Sáez, PhD

Jon Mikel Zabala-Iturriagagoitia, PhD

Jose Luis Zofío, Professor

This paper evaluates to what extent policy-makers have been able to promote the creation and consolidation of comprehensive research groups that contribute to the implementation of a successful innovation system. Malmquist productivity indices are applied in the case of the Spanish Food Technology Program, finding that a large size and a comprehensive multi-dimensional research output are the key features of the leading groups exhibiting high efficiency and productivity levels. While identifying these groups as benchmarks, we conclude that the financial grants allocated by the program, typically aimed at small-sized and partially oriented research groups, have not succeeded in reorienting them in time so as to overcome their limitations. We suggest that this methodology offers relevant conclusions to policy evaluation methods, helping policy-makers to readapt and reorient policies and their associated means, most notably resource allocation (financial schemes), to better respond to the actual needs of research groups in their search for excellence (micro-level perspective), and to adapt future policy design to the achievement of medium-long term policy objectives (meso and macro-level).

\section{Answers to the reviewer comments}

1.- We agree with the referee in this point. R\&D policy evaluation, due to a rather uncertain result of its influence, becomes more rigorous if a combination of qualitative and quantitative techniques is applied. In this paper we apply a quantitative technique based on the information provided by researchers (who got their projects granted) directly to the funding body. This information is a mix of quantitative and qualitative data. However, and being aware of this weakness, we incorporate the qualitative information from previous analyses that the authors have obtained with regard to the same SFTP.

2.- We agree with the referee's comment on how the efficiency/inefficiency rate is shared among the research groups participating into the SFTP, and the financial support it provides. We rely on previous research to construct the four-categories typology of research groups (comprehensive, specialized, partially oriented and shooting stars) that also match with a previous three-category typology (consolidated, 
emerging and shooting stars) presented in Jiménez-Sáez (2004), as referred to in the paper.

3.- Right now we are in the process of incorporating the information of research projects financed between 2000 and 2004, which represents a new R\&D Plan. This information is rather fragmented in different administration bodies, reason why it takes some years to obtain the results of projects financed in this last decade.

4.- We very much subscribe that an interesting line of research is opened by the combination of quantitative and qualitative approaches aimed at the evaluation of policy instruments. In this regard there is an interesting stream of research which has introduced the concepts of input, output and behavioral additionality as methodologies to assess (both quantitatively and qualitatively) the "success" or a certain policy. In the particular case of the paper, we don't discuss this conceptual and methodological approach since the data do not allow us to apply any of the additionality approaches (see Georghiou and Clarisse, 2006). However, the distance function introduced in (1) allows to balance the output or input orientation when calculating the efficiency of research groups. When the a parameter introduced in (1) quals one: $\alpha=1$, the generalized distance function equals the output distance function $D_{0}(x, y)=$ min $(\Phi>0:(x, y / \Phi) \varepsilon T)$, while if $\alpha=0$ it is equivalent to the input distance function, $D_{1}(x, y)=\max (y>0:(x / y, y) \varepsilon T)$. Finally, if $\alpha=0.5$ equation (2) becomes the square of the hyperbolic graph distance function. The flexibility in the a parameter has relevant implications for our research, as it opens opportunities for the further development of DEA approaches, including qualitative values in the estimation of the distance function. In fact, one could (for example as a result of making interviews with the researchers and policy-makers involved in the SFTP) define a new value for $\alpha$, which could take into consideration qualitative assessments by these stakeholders. E.g. SFTP managers might be interested in increasing outputs and reducing inputs in a different proportion than considered in our study, which is neutral: $\alpha=0.5$, while research groups would certainly want to be evaluated from an output orientation, since the input orientation would force them to increase productivity with less resources. The idea of setting a direction based in qualitative information (interviews) with the different agents involved in the SFTP has not been done so far-to the best of our knowledge, and constitutes definitely an interesting path for us to pursue.

5.- In fact, it could be argued that in order to avoid the identification of efficient research groups by default using DEA (or force the production frontier to be determined by an specific subset of DMUs), we could impose weight restrictions on the multipliers of the DEA program solving for the hyperbolic efficiency. That way we could include subjective judgments on the parts of the agents involved in the SFTP or prior knowledge. This can be achieved in several ways: e.g., by imposing upper and lower bounds on individual multipliers; imposing bounds on ratios of multipliers, appending multiplier inequalities, requiring multipliers to belong to given closed cones, etc. -see Cooper et. al (2004) for an introduction to this methodology and Beasley (1990) for its application to university departments; or, following the approach proposed by Halme et al. (1999), which is closer to our study, to aid the research manager in searching for the most preferred combination "solution" of inputs and outputs, i.e. the use of Value Efficiency Analysis -see its particular application to academic research by Korhonen et al. (2001). However, we adopted none of these approaches because: a) we wanted to identify those research groups that show up as efficient by specialization in a particular dimension, as this is a behaviour consciously adopted by some researchers; and b) from a methodological perspective, incorporating value judgments or prior information requires previous studies capable of producing that knowledge-i.e. efficiency analyses such as the one we perform here or the already mentioned by Jiménez-Sáez (2004), would be necessary. How this can be translated into policy recommendations for R\&D managers so that they will not be influenced by the efficiency scores from inappropriate benchmarks in allocating funds is an easy task, resolved by recommending that it is particular input/output combinations that should be used as the basis for funding. Finally, as previously mentioned, our neutral approach to preferred input-output combinations is evident in our choice of the alpha parameter, which places equal weight on inputs and outputs, i.e. $\alpha=0.5$

6.- It is certainly the case that our data set has several zero entries on the outputs side, which is a fundamental characteristic of the decision-making process of research groups, i.e. they are the result of conscious behavior. From a computational point of view we followed the theoretical results presented in Thomson et al. (1993), who state that if a complementary pattern of input or output zeros exists, then the DEA efficiency measures of the DMU's subdomain obtained by excluding those presenting variables 
with zero values, are the same as those for the complete data domain including all DMUs - Theorem 9A in Charnes et al. (1991).

7.- We find the comment made by the reviewer as being very accurate. However, it is hard to make an inclusive comparison among policy instruments across countries. The heterogeneity among technology support programs is extensive, as well as the evaluation processes followed in them. Some programs are oriented at increasing the technical capabilities of firms, others aim at developing new scientific contributions, while others emphasize the necessary links between the scientific exploration and the economic exploitation of these results. In this regard, we have found some contributions which are very much related to the conclusions in our paper. Schmoch and Schubert (2009) discuss the need to include a wide set of indicators when attributing excellence to the behavior of certain research units. We find that their conclusions are very much illustrated by our case study, where we use a wide battery of indicators. Trabada (2000) also finds the lack of international/European orientation of Spanish food technology groups, when evaluating the degree to which they participate in European technology programs. His results are also confirmed by those of Garcia Martinez and Briz (2000) and ourselves as to the lack of interaction between firms and research groups in the Spanish food related fields. These references have accordingly been introduced in the paper.

\section{References:}

Beasley, J. E. 1990. Comparing University Departments. Omega 18(2) 171-183. Charnes, A., W.W. Cooper, R.M. Thrall. 1991. A Structure for Classifying and Characterizing Efficiencies and Inefficiencies in Data Envelopment Analysis. Journal of Productivity Analysis 2 197-237.

Cooper, W.W., L.M. Seiford, J. Zhu. 2004. Handbook on Data Envelopment Analysis. Kluwer Academic Publishers, Norwell (Mass.).

Georghiou, L., Clarysse, B. (2006) Introduction and Synthesis. Government R\&D Funding and Company Behaviour: Measuring Behavioural Additionality OECD. Paris, OECD Publisher.

Halme, M., T. Joro, P. Korhonen, S. Salo, J. Wallenius. 1999. A Value Efficiency Approach to Incorporating Preference Information in Data Envelopment Analysis. Management Science 45(1) 103-115.

Korhonen, P., R. Tainio, Wallenius, J. 2001. Value Efficiency Analysis of Academic Research. European Journal of Operational Research 130 121-132.

Thomson, R.G., P.S. Dharmapala, R.M. Thrall. 1993. Importance for DEA of Zeros in Data, Multipliers, and Solutions. Journal of Productivity Analysis 4 379-380.

Trabada, F. (2000) Food technology in Spain. CDTI's and EUREKA's perspectives, Food Research International, 33: 299-304.

Schmoch, U., Schubert, T. (2009) Sustainability of incentives for excellent research The German case, Scientometrics, 81(1): 195-218.

Changes made in the paper based on the reviewer comments

1.- In order to clarify in the paper the reasons underlying the election of Malmquist productivity analysis technique for the paper, we incorporate the following paragraph into the page 6 , at the beginning of section 3 :

Besides offering a dynamic view of the SFTP, we also incorporate some qualitative information on how researchers involved in the programme have assessed their participation along with the results attained with their projects. Anyhow, we rely on a rather quantitative technique since it is able to incorporate a dynamic perspective on the evolution of the SFTP and on researchers' performance after their participation in it.

2.- In order to reinforce the participation of research groups into the four-category typology presented in the paper and how these productive/non-productive groups participate into the SFTP, we add the following paragraph at page 18 in section 7.1: Considering the whole period of time, if we relate our results to those presented by Jiménez-Sáez (2004) we can conclude that research groups leading productivity gains have only captured a small proportion of the SFTP financial support (less than $30 \%$ ), while they have been engaged in the generation of a larger proportion of research results in any category (more than $40 \%$ of results).

3.- We have introduced a new footnote on page 7 , after "a balanced weight is given by $\alpha=0.5$ as $\alpha /(1-\alpha)=1 "$. 
The $\alpha=0.5$ parameter also implies that no previous judgment has been introduced in the evaluation, so both inputs and outputs are given the same weight. Interviews with researchers and managers in charge of the R\&D policy would however allow us to include their views on the evaluation, putting more emphasis on either inputs or outputs. We believe this research could contribute to establish more solid bridges between quantitative and qualitative assessment methodologies.

4.- According to the answer given to the comment 7 above, the following paragraph has been included in the conclusions of the paper, right after the point $v$ (page 26): There are some limitations to this study which encourage further research efforts. One of these is the focus on a single national program which affects the degree to which our conclusions can be generalized to other research environments. That would allow policy-makers to benefit from the application of the conclusions obtained not only in countries where similar practices are implemented, but also on those where similar research group distributions are observed. In this sense, Schmoch and Schubert (2009), discuss the need to include a wide set of indicators when attributing excellence to the behavior of certain research units. We find that their conclusions are very much illustrated by our case study, where we also use a wide array of indicators.

References included in the paper SCHMOCH, U., SCHUBERT, T. (2009) Sustainability of incentives for excellent research - The German case, Scientometrics, 81(1): 195-218. 


\title{
Who leads research productivity growth? Guidelines for R\&D policy-makers
}

\author{
Fernando Jiménez-Sáez ${ }^{\mathrm{a}}$, Jon Mikel Zabala-Iturriagagoitia ${ }^{\mathrm{b} *}$, Jose Luis Zofío ${ }^{c}$
}

Affiliations:

a.- INGENIO (CSIC-UPV), Universidad Politécnica de Valencia, Camino de Vera s/n, 46022, Valencia (Spain)

b.- CIRCLE, Lund University. Solvegatan 16, PO Box 117, SE-22100, Lund (Sweden)

c.- Departamento de Análisis Económico: Teoría Económica e Historia Económica, Universidad Autónoma de Madrid, 28049, Cantoblanco, Madrid (Spain)

* Corresponding author: Tel. +46 (0) 4622233 62; Fax: +46 (0)46 2224161.

E-mail address: jon mikel.zabala@circle.lu.se

\begin{abstract}
This paper evaluates to what extent policy-makers have been able to promote the creation and consolidation of comprehensive research groups that contribute to the implementation of a successful innovation system. Malmquist productivity indices are applied in the case of the Spanish Food Technology Program, finding that a large size and a comprehensive multi-dimensional research output are the key features of the leading groups exhibiting high efficiency and productivity levels. While identifying these groups as benchmarks, we conclude that the financial grants allocated by the program, typically aimed at small-sized and partially oriented research groups, have not succeeded in reorienting them in time so as to overcome their limitations. We suggest that this methodology offers relevant conclusions to policy evaluation methods, helping policy-makers to readapt and reorient policies and their associated means, most notably resource allocation (financial schemes), to better respond to the actual needs of research groups in their search for excellence (micro-level perspective), and to adapt future policy design to the achievement of medium-long term policy objectives (meso and macro-level).
\end{abstract}

Keywords: Science and technology policy; Policy evaluation; Malmquist productivity index; Data Envelopment Analysis.

JEL codes: C43, D24, O47.

MSC codes: 19A15, 91B38, 91B82. 


\section{Introduction}

Public support to Research and Development (R\&D) and technology transfer activities are totally incorporated into Spanish Science and Technology (S\&T) policies. However, the evaluation of these activities is not fully internalized into the policy cycle yet. Furthermore, the evaluation processes carried out so far deal with the elaboration of static indicators which barely provide an accurate picture regarding the way the results of these activities are evolving over the time. In addition, many scholars claim that the structuralist-evolutionary context under which these sorts of policies are being built (Lipsey et al. 2005) need an alternative evaluation context, different to the efficiency of outcomes in a return on investment sense (Potts 2007).

Another important claim that policy-makers and scholars raise with respect to these activities' outcomes and impacts is the need for a long term perspective to be able to actually appreciate them into the territory. However, this is an issue that has not been extensively treated in the policy evaluation literature. Moreover, this totally fair claim implies that conventional short term-cross section - evaluation processes of these activities might render narrow results that do not shed light on issues that could be useful to establish guidelines for long run policy reorientations. Therefore an evaluation methodology that provides a dynamic overview on the evolution of R\&D and technology transfer activities should be able to capture, on the one hand, the behavioral evolution (Buisseret et al. 1995) of the agents participating in the policy (i.e. the micro-level perspective) and the complexity of the economic order that S\&T policies pose on any given innovation system on the other (i.e. the macro-level perspective).

This paper proposes a long term evaluation framework for a Spanish public policy supporting $R \& D$ and technology transfer activities within the food technology field based on efficiency and productivity measures. To offer this dynamic view on the impacts and outcomes that such policy has shown we follow a threefold perspective: micro, meso and macro. The micro-level perspective constitutes the focus of our study (research groups participating within the food technology field in Spain), the meso-level represents the plane where the recommendations to be concluded from the study are to be applied (Spanish S\&T policy), while the macro-level corresponds to the context of analysis (Spanish food innovation system). Our goal is to determine the policy impact on the research groups' outputs (micro-level perspective), to gauge to what extent the policy contributes to consolidate the research groups' position on the food technology field (meso-level perspective), and how this relative position is helping the policy to construct a complex and articulated innovation system on the referred field (macro-level perspective). That is, we aim to contribute to the literature with a dynamic framework that could offer a set of guidelines for decision-makers involved in the management of multi-level S\&T policies (Laranja et al. 2008).

Studying the evolution of the system in time implies determining the characteristics of the most successful agents from a dynamic perspective - which in turn implies sorting them out according to their heterogeneity, so as to categorize those best practices that allow R\&D managers to change 
policy guidelines in a way that encourages less successful agents to adopt benchmark practices. Our study performs such dynamic analysis and the results provide $R \& D$ managers with consistent evidence of those best practices over time, which will allow them to design and implement new strategies (financial schemes and their associated requirements) that would render the system more efficient and productive.

In order to accomplish this target, we perform a Malmquist Productivity Index (MPI) analysis that helps us understand how the policy is affecting the research groups participating into this policy. The paper focuses on research groups within the food technology sector that belong to the Spanish National Research Council (CSIC) and that have participated in the Spanish Food Technology Program (SFTP) between 1988 and 1999. We explore how our methodological approach allows to: (i) analyze the behavior and interactions of agents within the innovation system, and their effect on the productivity; (ii) contribute to policy evaluation and the sort of recommendations that will emerge under this approach.

From this micro-level perspective, our analysis is able to capture the degree of heterogeneity among research groups, both in terms of their research behavior and productive scale-i.e., relative size. This fact combined with the temporal perspective helps us characterize the contribution of research groups to the articulation of the innovation system as the final policy goal from the macrolevel perspective. However, policy-makers do act in the meso-level (Dopfer et al. 2004). Hence, our conclusions are addressed to provide them with guidelines in terms of what characteristics allow research groups to increase their internal capabilities and how that evolution fosters the innovation system towards an articulated one. Therefore policy-makers can reorient and adjust the policy in specific directions that provide agents with the incentives to change in the desired direction. This is in fact the case of R\&D managers in the food technology field, whose policy guidelines regarding the funding of particular projects and research groups have changed over the years in a way that is consistent with our results by promoting research activities of groups performing multidimensional and comprehensive research that contribute to the articulation of the innovation system, and exhibit higher efficiency and productivity levels.

The paper is structured as follows. The next section discusses the approaches that have been proposed in the literature to assess the dynamics of an innovation system and the policies related to it. This is followed by a discussion of the institutional framework that characterizes the Spanish Food Technology Program (SFTP) and the research units participating in it. Next, we present the technology and its representation by way of the generalized distance function. In section 5 we present the definition of the MPI and its decomposition in different terms, which allows us to determine the contribution that technological change, technical efficiency change and scale efficiency change make to productivity change. Generally, the decompositions of the MPI found in the literature are based on a changing base approach, whose main consequence is that the indices do not comply with the circularity property that allow consistent aggregation of period by period and sub-period productivity 
changes. To avoid this weakness that would not allow us to carry out a dynamic analysis, we introduce the necessary chained index definitions of all the alternative decompositions, which will be later used in the empirical application. In section 6 we concisely present the Data Envelopment Analysis (DEA) techniques that allow calculation of the generalized distance functions on which the MPI is based. We undertake our empirical analysis of productivity change in section 7 , where the productivity trends of the different research units involved in the SFTP are presented and the different sources of productivity change discussed. Section 8 concludes illustrating to what extent the SFTP has fostered productivity growth among those research units that have obtained financial support within the Spanish R\&D plan.

\section{Public policies and the promotion of research: towards a dynamic assessment}

Within the field of economics of science and technological change, two opposite streams of literature determine different arguments favoring public intervention. According to the neoclassical approach, public intervention rests on the existence of market failures and production of new knowledge is associated with a positive externality (Arrow 1962). The structuralist-evolutionary approach on the other hand, sees knowledge as an imperfect good that does not satisfy the usual characteristic of non-excludability, so the agents generating it will only be able to appropriate a small fraction of the social benefit produced (David et al. 1994). This approach is also linked to the concept of Innovation System (IS), which justifies the existence of different agents and the relationships among them to carry out innovation activities (Freeman 1987; Lundvall 1992). Therefore, under a structuralist-evolutionary approach, $R \& D$ public policies, to an extent, respond to the need to strengthen the role and involvement of IS agents (Lipsey and Carlaw 1998; Metcalfe 2002).

This interactive behavior relates to Rip and Nederhof's (1986) terminology of IS's articulation. Their concept of articulation correlates with the description in Gibbons et al. (1994) of the change in scientific knowledge production from mode $\mathrm{I} \longrightarrow$ summarized as the pursuit of scientific truth by scientists - to mode II- the production of knowledge from application-and the succeeding relationships among agents. Hence an articulated IS enables the different types of agents (i.e. policymakers, scientists, technologists, business men, etc.) to maintain continuity in their relationships, over time. By relying on this articulation concept, we aim to assess the Spanish Food Innovation System's (SFIS) capacity to establish a network of fluent and continuous knowledge flows among its constituting agents.

In this paper we focus on the impact that the Spanish Food Technology Program has had on the research groups within the food technology field in Spain, as one of the most relevant instruments used by Spanish S\&T policies to encourage and support the articulation of the IS. From this perspective we want to link the idea of public policies promoting a growing multidimensional output of research units, as an instrumental policy goal toward the articulation of a successful IS. To assess whether this instrumental goal has been successful we evaluate such policy using productivity 
analysis. In particular, we will analyze the productivity gains observed in the research groups that belong to the CSIC. Our research question is thus: to what extent has the SFTP become a suitable tool to promote the productivity increases of research units (micro level) contributing therefore to a multidimensional research output mix and, by extension, to the SFIS's articulation (meso level)?

One of the main limitations of the existing studies on the evaluation of innovation policies is the static view they offer. The literature agrees that innovation is a dynamic phenomenon (Autio 1997) and there is still a strong need to study the trends in technological change (Grimpe and Sofka 2007). Lee and von Tunzelman (2005) consider that the study of systems through time allows for the analysis of complex behaviors that shed light on how policies, decisions, structure, and delays are interrelated and influence growth and stability. In recent years, there have been attempts to provide the IS approach with a more dynamic view. Markard and Truffer (2008) follow an actor-oriented perspective relating the micro (individual strategies and resources) and meso (system characteristics) levels in the case of stationary fuel cells in Germany. Similarly, Miettinen (1999) illustrates the possibilities of studying the dynamics of research-driven innovations using activity and actor-network theories. In addition, the literature discerns a series of functions accomplished within the frame of IS as one of the main attempts to characterize these system dynamics (Balzat and Hanusch 2004). In contrast to the traditional agent-based view of innovation, which mainly focuses on the structure or a certain system, the functions view of innovation is based on mapping the activities that result in technological change and finally in the performance of an IS (Bergek et al. 2008; Edquist and Hommen 2008; Hekkert et al. 2007).

However, not only the dynamic assessment of an IS becomes a key issue, but also that of the innovation policies supporting its future development. In fact, the evolution followed by the IS approach and science, technology and innovation policies show an interactive and co-evolving process (Molas-Gallart and Davies 2006; Mytelka and Smith 2002). Accordingly, the innovation policy evaluation related literature is also challenged by the need to provide policy evaluations with a dynamic view (Arbel 1981; Kuhlmann 2003; van Raan 2000). This change in the role of evaluation in policy-making has also implications in the rationales for intervention, the behavior of institutions and framework conditions, and last but not least the role of the policy-maker (Arnold 2004).

From a policy management perspective few are the efforts done in the evaluations of the innovation policy instruments implemented so as to assess their influence and results in the long run, both on the actors the policy is oriented to (micro level) and on the conclusions that may be drawn on the policy (meso) level. A recent contribution is done by Grammatikopoulos et al. (2004) in education policies in Greece, following a temporal evaluation approach. Schmidt et al. (2003), in turn, conclude about the organization and leadership of research environments; the framework and the conditions for research; and the resource allocation policy as the key drivers of research policies in Denmark. From an industrial perspective, one of the few contributions is that of Laitinen (2002) who presents the results of a dynamic integrated performance measurement system applied to small Finnish technology 
companies. ${ }^{1}$ This is precisely our major target, to provide policy-makers with a tool to dynamically assess the performance of the research units the policy is aimed at.

\section{The Spanish Food Technology Program institutional framework}

The SFTP was launched in 1988 within the 1 st national R\&D plan and has been an element in all its subsequent announcements. ${ }^{2}$ Its financial support represents around $5 \%$ of the overall national R\&D Plan budget (Jiménez-Sáez 2005). Thus, based on the amount of resources devoted to SFTP, the importance of evaluating it in order to assess whether and to what extent its original objectives have been achieved is evident. The evaluation in this study could also serve as a model for the other programs within the national R\&D plan. In addition, this investigation will complement other analyses and evaluations in this context (Acosta Ballesteros and Modrego Rico 2001; Jiménez-Sáez et al. 2011) and will contribute to filling the gap in Spanish R\&D public policy evaluation (Bustelo, 2006). Besides offering a dynamic view of the SFTP, we also incorporate some qualitative information on how researchers involved in the programme have assessed their participation along with the results attained with their projects. Anyhow, we rely on a rather quantitative technique since it is able to incorporate a dynamic perspective on the evolution of the SFTP and on researchers' performance after their participation in it. The SFTP as set forth in the original 1988 call was defined as a:

systematic group of research and development projects oriented towards the encouragement of research, technology innovation and development in the Spanish Food Technology sector. It is coordinated and complemented by other actions among which the training of specialized personnel ${ }^{3}$ and the establishment of an infrastructure that favors technology transfer from knowledge producing sectors to users stand out (CICYT 1988).

Four major milestones constitute the central goal of the SFTP: (i) training personnel; (ii) support for firm R\&D and innovation activities; (iii) support for research groups' $R \& D$ activities; and (iv) support for technology transfer from research groups to firms (CICYT 1987). The SFTP, as other R\&D programs within the Spanish R\&D plan—as well as in many other countries having similar programs, was designed to cover all the stages in the innovation process, offering possibilities for participation to a wide variety of agents, and fostering co-operation among them. The present study focuses on the support for research groups' $R \& D$ activities, which is mainly intended to provide financial support to research groups at public research organizations in order to carry out applied

\footnotetext{
${ }^{1}$ For a more theoretical contribution about how to carry out a dynamic evaluation, the reading of Abbring and Heckman (2008) is recommended.

${ }^{2}$ In the last National Research, Development and Innovation Plan 2008-2011, the SFTP has adopted a new name, "Agrarian and Food Biotechnology", which is included in the strategic line of biotechnology.

${ }^{3}$ The SFTP originally included in the training of specialized personnel two different outputs: young researchers (grant holders) finalizing their $\mathrm{PhD}$ thesis, and technical support personnel. The data for the analysis in this paper accounts for both these categories as completed PhD theses and technical trained personnel.
} 
research mainly embodied in international scientific publications, scientific personnel training, patent applications, etc. as the most relevant measurable outputs concerning scientific productivity.

The initial budget for the program in 1988 was approximately $€ 45$ million. The highest share of this budget was earmarked for the creation of infrastructures (33\% of the total budget), and support for R\&D activities through a variety of financial tools (26.7\%). Support for R\&D activities carried out by research groups at Public Research Organizations (PRO) was assigned to $R \& D$ projects whose commercial potential would be of interest to private firms. In addition, there was the possibility of cooperation between research groups and firms through bilateral contracts, which existed outside the SFTP financial scheme. It was expected that both sources of financial support would translate into a multidimensional research output that would eventually render not only science-technology outputs, but also training and socio-economic goals related to a trustful and lasting cooperation with the private sector.

\section{Technology and the Generalized Distance Function}

Consider a panel of $i=1, \ldots, \mathrm{I}$ research units observed in $t=1, \ldots, \mathrm{T}$ periods, transforming input vectors $x_{i}^{t}=\left(\mathrm{x}_{1 i}{ }^{t}, \ldots, \mathrm{x}_{\mathrm{N} i}{ }^{t}\right) \in \mathfrak{R}^{N}$. into output vectors $y_{i}^{t}=\left(\mathrm{y}_{1 i}{ }^{t}, \ldots, \mathrm{y}_{\mathrm{M} i}{ }^{t}\right) \in \mathfrak{R}^{M}$. Given these data, technology can be represented by the production possibility set of feasible input-output combinations: $\mathrm{T}^{t}=\{(x, y): x$ can produce $y$ at time $t\}, t=1, \ldots, \mathrm{T}$, which satisfies the usual axioms- (Shephard 1970). For $i$-th research unit, the production technology can be represented by the generalized distance function introduced by Chavas and Cox (1999):

$$
D_{\mathrm{G}}^{t}(x, y ; \alpha)=\min \left\{\delta>0:\left(x \delta^{1-\alpha}, y / \delta^{\alpha}\right) \in \mathrm{T}^{t}\right\}, \quad x \in \mathfrak{R}_{+}^{\mathrm{N}}, y \in \mathfrak{R}_{+}^{\mathrm{M}}
$$

where $0 \leq \alpha \leq 1$ represents the relative weight that the distance function places on outputs and inputs. As a result, it allows assigning asymmetric weights to the inputs and outputs vectors depending on the choice of $\alpha$, which is exogenously determined in the model. As we do not want to stress one particular dimension of the production process when measuring research efficiency, in this study we decide for a neutral direction that equally weights inputs contraction and outputs expansion - a balanced weight is given by $\alpha=0.5$ as $\alpha /(1-\alpha)=1 .{ }^{4}$ The generalized distance function places a research group on the best practice frontier represented by the boundary of the technology -defined as Isoq $\mathrm{T}^{t}=\{(x, y):(x, y) \in$ $\left.\mathrm{T}^{t},\left(\omega^{1-\beta} x, y / \omega^{\beta}\right) \notin \mathrm{T}^{t}, 0<\omega<1,0 \leq \beta \leq 1\right\}$, and can be interpreted as a measure of technical efficiency in the sense of Farrell (1957). That is, the distance separating a research group from the frontier given the

\footnotetext{
${ }^{4}$ The $\alpha=0.5$ parameter also implies that no previous judgment has been introduced in the evaluation, so both inputs and outputs are given the same weight. Interviews with researchers and managers in charge of the R\&D policy would however allow us to include their views on the evaluation, putting more emphasis on either inputs or outputs. We believe this research could contribute to establish more solid bridges between quantitative and qualitative assessment methodologies.
} 
productivity of its benchmark peers. If $D_{\mathrm{G}}^{t}\left(x^{t}, y^{t} ; \alpha\right)=1$ for a particular research unit, this observation is efficient, belonging to Isoq $\mathrm{T}^{t}$ and defining the frontier, while if $D_{\mathrm{G}}^{t}\left(x^{t}, y^{t} ; \alpha\right)<1$ it is inefficient laying inside the frontier.

Besides variable returns to scale, the technology $\mathrm{T}^{t}$ may exhibit global increasing, decreasing and constant returns to scale. In this latter case the technology $\mathrm{T}^{t}$ implies a mapping $x \rightarrow y$ that is linearly homogeneous of degree +1 , and may be denoted by $\hat{\mathrm{T}}=\{(\lambda x, \lambda y):(x, y) \in \mathrm{T}, \lambda>0\}$, while the generalized distance function corresponds to:

$$
\hat{D}_{\mathrm{G}}^{t}(x, y ; \alpha)=\min \left\{\delta>0:\left(x \delta^{1-\alpha}, y / \delta^{\alpha}\right) \in \hat{\mathrm{T}}^{t}\right\}, x \in \mathfrak{R}_{+}^{\mathrm{N}}, y \in \mathfrak{R}_{+}^{\mathrm{M}}
$$

This generalized distance function can be also interpreted as a measure of productive efficiency, placing an observation on the benchmark frontier represented by Isoq $\hat{\mathrm{T}}^{t}=\{(x, y):(x, y) \in$ $\left.\hat{\mathrm{T}}^{t},\left(\omega^{(1-\beta)} x, y / \omega^{\beta}\right) \notin \hat{\mathrm{T}}^{t^{t}}, 0<\omega<1,0 \leq \beta \leq 1\right\}$ - with the same numeric interpretation as its technical counterpart (Eq. 2). We can determine the scale efficiency of a research unit by comparing the distance functions defined on the variable and constant returns to scale technologies. Zofío and Prieto (2006) show that this comparison gauges the productive efficiency of a research unit at its particular productive scale (1), with respect to that of benchmark units operating at the most productive scale sizes (MPSSs) and whose production processes are characterized by constant returns to scale, i.e. the productive efficiency of the research unit as measured by (2). Relaying on these definitions, any difference between these distance functions can be interpreted as a measure of scale efficiency: $\mathrm{SE}^{t}$ $\left(x^{t}, y^{t} ; \alpha\right)=\operatorname{PE}^{t}\left(x^{t}, y^{t} ; \alpha\right) / \operatorname{TE}^{t}\left(x^{t}, y^{t} ; \alpha\right)=\hat{D}_{\mathrm{G}}^{t}\left(x^{t}, y^{t} ; \alpha\right) / D_{\mathrm{G}}^{t}\left(x^{t}, y^{t} ; \alpha\right)$.

\section{Decomposing the Malmquist productivity index (MPI)}

The Malmquist index is a ratio of two distance functions representing the change in productivity of a research unit observed in two consecutive periods, relative to a benchmark technology. We start out with the adjacent-period version of the fixed-based MPI. For any given unit $i$ observed in two consecutive periods, $\left(x_{i}^{t}, y_{i}^{t}\right)$ and $\left(x_{i}^{t+1}, y_{i}^{t+1}\right)$, and using the first period $t=1$ as the base technology, the fixed-based MPI defines as:

$$
\hat{\mathrm{M}}_{\mathrm{G}}^{1}\left(x_{i}^{t}, y_{i}^{t}, x_{i}^{t+1}, y_{i}^{t+1} ; \alpha\right)=\frac{\hat{D}_{\mathrm{G}}^{1}\left(x_{i}^{t+1}, y_{i}^{t+1} ; \alpha\right)}{\hat{D}_{\mathrm{G}}^{1}\left(x_{i}^{t}, y_{i}^{t} ; \alpha\right)},
$$

where the mix period generalized distance functions $\hat{D}_{\mathrm{G}}^{1}\left(x_{i}^{t}, y_{i}^{t} ; \alpha\right)$ and $\hat{D}_{\mathrm{G}}^{1}\left(x_{i}^{t+1}, y_{i}^{t+1} ; \alpha\right)$ define in an analogous way to (2). Taking the former as the illustrating case, $\hat{D}_{\mathrm{G}}^{1}\left(x_{i}^{t}, y_{i}^{t} ; \alpha\right)=$ 
$\min \left\{\delta>0:\left(x_{i}^{t} \delta^{1-\alpha}, y_{i}^{t} / \delta^{\alpha}\right) \in \hat{\mathrm{T}}^{1}\right\}, \quad x \in \mathfrak{R}_{+}^{\mathrm{N}}, y \in \mathfrak{R}_{+}^{\mathrm{M}}$, which compares subsequent periods research units to the base period technology.

Note that the distance functions comprised in the Malmquist index (3) are defined on the benchmark linearly homogeneous — constant returns to scale - technology. The reason is that in this case the generalized distance functions are linearly homogeneous of degree +1 in outputs and -1 inputs, i.e. the generalized distance function is homogeneous of degree zero in inputs and outputs: $\hat{D}_{\mathrm{G}}^{t}\left(\lambda x^{t}, \lambda y^{t} ; \alpha\right)=\hat{D}_{\mathrm{G}}^{t}\left(x^{t}, y^{t} ; \alpha\right), \lambda>0$, and, as commonly acknowledged in the literature, the Malmquist index can be considered as a productivity index by complying with the desirable proportionally property. ${ }^{5}$

While the MPI version presented in (3) ensures that the index satisfies the circular test (see Berg et al. 1992; Førsund 1993), it does not yield values cumulating throughout the whole period, but temporal trends corresponding to period to period variations - even if refereed to the base year, whose interpretation is not as straightforward as keeping a reference period constant. In long range studies as the one we perform here it seems appropriate to calculate productivity change relative to a fixed-base reference technology thus allowing productivity trends comparisons between subsequent periods. The formulation satisfying this cumulative version of the fixed-base MPI is the following:

$$
\hat{\mathrm{M}}_{\mathrm{G}}^{1}\left(x_{i}^{1}, y_{i}^{1}, x_{i}^{t}, y_{i}^{t} ; \alpha\right)=\frac{\hat{D}_{\mathrm{G}}^{1}\left(x_{i}^{t}, y_{i}^{t} ; \alpha\right)}{\hat{D}_{\mathrm{G}}^{1}\left(x_{i}^{1}, y_{i}^{1} ; \alpha\right)} \text {. }
$$

Thus, if any consecutive indices calculated as in (3), e.g. $\hat{\mathbf{M}}_{\mathrm{G}}^{1}(1,2)$ and $\hat{\mathrm{M}}_{\mathrm{G}}^{1}(2,3)$, are multiplied one would get $\hat{\mathrm{M}}_{\mathrm{G}}^{1}(1,3)$ defined as in (4). We now present the alternative ways in which (4) can be decomposed according to the alternative proposals suggested in the literature - while following Zofío and Lovell (2001) it would be possible to obtain the counterparts corresponding to (3), which are used in the empirical application to discuss productivity change between periods.

\subsection{First level decomposition of the chained MPI: technical and efficiency change}

For $\hat{D}_{\mathrm{G}}^{1}\left(x_{i}^{t}, y_{i}^{t} ; \alpha\right)$ it can be the case that $\left(x_{i}^{t}, y_{i}^{t}\right) \notin \hat{\mathrm{T}}^{1}$. As a result values of $\hat{D}_{\mathrm{G}}^{1}\left(x_{i}^{t}, y_{i}^{t}\right)>1$ would be verified in the presence of technological progress, whose contribution to (4) can be singled out by way of the following decomposition:

\footnotetext{
${ }^{5}$ It can be easily proved that the desirable proportionally property is satisfied by (6), i.e. $\hat{\mathrm{M}}_{\mathrm{G}}^{1}\left(x_{i}^{1}, y_{i}^{1}, x_{i}^{t}, y_{i}^{t}\right)=$ $\mathrm{M}_{\mathrm{G}}^{1}\left(x_{i}^{1}, y_{i}^{1}, \mu x_{i}^{t}, v y_{i}^{t}\right)=\mu / \nu$. Førsund (1997) summarizes this axiomatic approach to acknowledge any index as a productivity index, but the most relevant one in our current Malmquist framework is the proportionality property, stating that if outputs (inputs) are increased (decreased) in the same proportion from one period to the next while
} 


$$
\begin{aligned}
\hat{\mathrm{M}}_{\mathrm{G}}^{1}\left(x_{i}^{1}, y_{i}^{1}, x_{i}^{t}, y_{i}^{t} ; \alpha\right) & =\frac{\hat{D}_{\mathrm{G}}^{1}\left(x_{i}^{t}, y_{i}^{t} ; \alpha\right)}{\hat{D}_{\mathrm{G}}^{1}\left(x_{i}^{1}, y_{i}^{1} ; \alpha\right)}=\frac{\hat{D}_{\mathrm{G}}^{1}\left(x_{i}^{t}, y_{i}^{t} ; \alpha\right)}{\hat{D}_{\mathrm{G}}^{t}\left(x_{i}^{t}, y_{i}^{t} ; \alpha\right)} \cdot \frac{\hat{D}_{\mathrm{G}}^{t}\left(x_{i}^{t}, y_{i}^{t} ; \alpha\right)}{\hat{D}_{\mathrm{G}}^{1}\left(x_{i}^{1}, y_{i}^{1} ; \alpha\right)}= \\
& =\operatorname{PTC}_{\mathrm{G}}^{1, t}\left(x_{i}^{t}, y_{i}^{t} ; \alpha\right) \cdot \mathrm{EC}_{\mathrm{G}}^{1, t}\left(x_{i}^{1}, y_{i}^{1} ; x_{i}^{t}, y_{i}^{t} ; \alpha\right) .
\end{aligned}
$$

Following Färe et al. (1994), hereafter FGNZ, technical change $\operatorname{PTC}_{\mathrm{G}}^{1, t}\left(x_{i}^{t}, y_{i}^{t} ; \alpha\right)$, and efficiency change $\mathrm{EC}_{\mathrm{G}}^{1, t}\left(x_{i}^{1}, y_{i}^{1}, x_{i}^{t}, y_{i}^{t} ; \alpha\right)$ can be interpreted as follows: $\operatorname{PTC}_{\mathrm{G}}^{1, t}\left(x_{i}^{t}, y_{i}^{t} ; \alpha\right)$ would capture the shift in the technology between periods 1 and $t$ using the fixed benchmark frontier as reference, while $\mathrm{EC}_{\mathrm{G}}^{1, t}\left(x_{i}^{1}, y_{i}^{1}, x_{i}^{t}, y_{i}^{t} ; \alpha\right)$ would measure the change in relative efficiency, i.e. how far observed production is from maximum potential production. However, Griffel-Tatjé and Lovell (1999) and Ray and Desli (1997), hereafter RD, argue against the technical change interpretation since its commonly accepted definition refers to shifts in the production technology for a given scale (allowing for a variable returns technology) and not changes in the supporting virtual (constant returns to scale) technologies. Zofío (2007) shows that $\operatorname{PTC}_{\mathrm{G}}^{1, t}\left(x_{i}^{t}, y_{i}^{t} ; \alpha\right)$ captures the change in potential technical change between units operating at the most productive scale sizes, MPSSs - where units are both technical and scale efficient - in two consecutive periods. We term it potential because is measures the maximum productivity change that could be achieved by any unit if it were fully efficient. Therefore $\operatorname{PTC}_{\mathrm{G}}^{1, t}\left(x_{i}^{t}, y_{i}^{t} ; \alpha\right)$ may be viewed as the highest potential productivity change in the absence of inefficiency — either from technical or scale reasons - and therefore measures productivity change between the highest observed productivities in the two periods. On the other hand, equal reasoning applies to the efficiency change term, which truly measures how far a unit is from the benchmark cone productivity and the best practice variable returns to scale frontier, and therefore would comprise both technical and scale efficiency change terms - as FGNZ (1994) would render later on explicit in their enhanced and final decomposition.

\subsection{Second level decomposition of the MPI: accounting for scale}

The fact that the supporting technology to correctly define productivity indices requires constant returns to scale does not mean that the underlying technology may not exhibit variable returns to scale. In fact, when identifying the contribution of returns to scale and scale efficiency one implicitly assumes that these terms are relevant sources of productivity change and, therefore, must be included in the analysis. Hence we begin this subsection presenting the decomposition independently introduced by Simar and Wilson (1998) and Zofío and Lovell (1998), hereafter jointly denoted by SWLZ (1998), and show that the two remaining proposals identifying the role that scale plays in

inputs (outputs) remain the same, then the productivity index must increase (decreased) in the same proportion. 
productivity change can be recovered from it — namely FGNZ (1994) and RD (1997), providing a unifying framework where one may deal with a complete characterization of technological and efficiency change. In the light of this contribution we rely on a comprehensive decomposition of the MPI whose terms can be correctly interpreted by retaining and complying with generally accepted definitions commonly accepted in the literature.

The MPI (5) can be further decomposed by splitting potential technical change and efficiency change into four new terms that allow determining the contribution that returns to scale and scale efficiency change make to productivity change. These contributions can be determined by way of the so-called scale bias of technical change introduced by SWLZ (1998). Starting with $\operatorname{PTC}_{\mathrm{G}}^{1, t}\left(x_{i}^{t}, y_{i}^{t} ; \alpha\right)$ measuring potential productivity change at the reference optimal scale over time from the $i$-th unit perspective, it can be decomposed as follows:

$$
\begin{aligned}
\operatorname{PTC}_{\mathrm{G}}^{1, t}\left(x_{i}^{t}, y_{i}^{t} ; \alpha\right) & =\frac{D_{\mathrm{G}}^{1}\left(x_{i}^{t}, y_{i}^{t} ; \alpha\right)}{D_{\mathrm{G}}^{t}\left(x_{i}^{t}, y_{i}^{t} ; \alpha\right)} \cdot \frac{\hat{D}_{\mathrm{G}}^{1}\left(x_{i}^{t}, y_{i}^{t} ; \alpha\right) / D_{\mathrm{G}}^{1}\left(x_{i}^{t}, y_{i}^{t} ; \alpha\right)}{\hat{D}_{\mathrm{G}}^{t}\left(x_{i}^{t}, y_{i}^{t} ; \alpha\right) / D_{\mathrm{G}}^{t}\left(x_{i}^{t}, y_{i}^{t} ; \alpha\right)}= \\
& =\mathrm{TC}_{\mathrm{G}}^{1, t}\left(x_{i}^{t}, y_{i}^{t} ; \alpha\right) \cdot \operatorname{STC}_{\mathrm{G}}^{1, t}\left(x_{i}^{t}, y_{i}^{t} ; \alpha\right)= \\
& =\frac{D_{\mathrm{G}}^{1}\left(x_{i}^{t}, y_{i}^{t} ; \alpha\right)}{D_{\mathrm{G}}^{t}\left(x_{i}^{t}, y_{i}^{t} ; \alpha\right)} \cdot \frac{\hat{D}_{\mathrm{G}}^{1}\left(x_{i}^{t}, y_{i}^{t} ; \alpha\right) / \hat{D}_{\mathrm{G}}^{t}\left(x_{i}^{t}, y_{i}^{t} ; \alpha\right)}{D_{\mathrm{G}}^{1}\left(x_{i}^{t}, y_{i}^{t} ; \alpha\right) / D_{\mathrm{G}}^{t}\left(x_{i}^{t}, y_{i}^{t} ; \alpha\right)}= \\
& =\mathrm{TC}_{\mathrm{G}}^{1, t}\left(x_{i}^{t}, y_{i}^{t} ; \alpha\right) \cdot \operatorname{PTC}_{\mathrm{G}}^{1, t}\left(x_{i}^{t}, y_{i}^{t} ; \alpha\right) / \mathrm{TC}_{\mathrm{G}}^{1, t}\left(x_{i}^{t}, y_{i}^{t} ; \alpha\right),
\end{aligned}
$$

where $\operatorname{TC}_{\mathrm{G}}^{1, t}\left(x_{i}^{t}, y_{i}^{t} ; \alpha\right)$ captures the shift in the best practice variable returns to scale frontier technology from the unit's comparison period $t$ perspective, and $\operatorname{STC}_{\mathrm{G}}^{1, t}\left(x_{i}^{t}, y_{i}^{t} ; \alpha\right)$ represents the scale bias against or in favor of the reference research unit scale. This can be easily shown rearranging $\operatorname{STC}_{\mathrm{G}}^{1, t}\left(x_{i}^{t}, y_{i}^{t} ; \alpha\right)$ as in the third line of (6). The numerator corresponds to potential technical change at optimal scale while the denominator corresponds to productivity change coming from technical change at the reference scale, i.e. $\operatorname{STC}_{\mathrm{G}}^{1, t}\left(x_{i}^{t}, y_{i}^{t} ; \alpha\right)=\operatorname{PTC}_{\mathrm{G}}^{1, t}\left(x_{i}^{t}, y_{i}^{t} ; \alpha\right) / \mathrm{TC}_{\mathrm{G}}^{1, t}\left(x_{i}^{t}, y_{i}^{t} ; \alpha\right)$.

Zofío (2007) extensively discusses how $\operatorname{STC}_{\mathrm{G}}^{1, t}\left(x_{i}^{t}, y_{i}^{t} ; \alpha\right)$ can be soundly obtained from a production perspective. Here we just stress its numeric meaning. If $\operatorname{STC}_{\mathrm{G}}^{1, t}\left(x_{i}^{t}, y_{i}^{t} ; \alpha\right)>1$, productivity gains reflected by the technical change at the research unit's comparison period scale does not match the potential productivity change observed at the optimal scales - the change in the MPSSs from the base to the comparison period, and accordingly, technical change at the unit's scale has to be augmented with an additional productivity gain if it is to match that one at optimal scale. Therefore, we can conclude that the change in the technology with regard to optimal scale presents a bias against the research unit's scale since it outgrows technical change at the research unit's particular scale -i.e. 
the change in the reference optimal scale works against the unit's scale with regard to productivity change, which would be the interpretation for $\operatorname{STC}_{\mathrm{G}}^{1, t}\left(x_{i}^{t}, y_{i}^{t} ; \alpha\right)$ when expressed as in the first line of (6). Contrarily, when $\operatorname{STC}_{\mathrm{G}}^{1, t}\left(x_{i}^{t}, y_{i}^{t} ; \alpha\right)<1$, productivity change at the reference scale exceeds productivity change at the optimal scale, and consequently technical change has to be decreased in the amount necessary to match productivity change at optimal scale. Therefore, the change in the technology with regard to optimal scale presents a bias in favor of the evaluated research unit's scale -i.e. the scale bias of technical change works in favor of the unit's scale. Finally, $\operatorname{STC}_{\mathrm{G}}^{1, t}\left(x_{i}^{t}, y_{i}^{t} ; \alpha\right)=1$ shows that the scale bias of technical change is neutral since productivity change at the reference scale matches productivity change at optimal scale, as would be the case in the presence of constant returns to scale.

We now decompose the efficiency change term $\operatorname{EC}_{\mathrm{G}}^{1, t}\left(x_{i}^{1}, y_{i}^{1}, x_{i}^{t}, y_{i}^{t} ; \alpha\right)$ into the following terms:

$$
\begin{aligned}
\operatorname{EC}_{\mathrm{G}}^{1, t}\left(x_{i}^{1}, y_{i}^{1}, x_{i}^{t}, y_{i}^{t} ; \alpha\right) & =\frac{D_{\mathrm{G}}^{t}\left(x_{i}^{t}, y_{i}^{t} ; \alpha\right)}{D_{\mathrm{G}}^{1}\left(x_{i}^{1}, y_{i}^{1} ; \alpha\right)} \cdot \frac{\hat{D}_{\mathrm{G}}^{t}\left(x_{i}^{t}, y_{i}^{t} ; \alpha\right) / D_{\mathrm{G}}^{t}\left(x_{i}^{t}, y_{i}^{t} ; \alpha\right)}{\hat{D}_{\mathrm{G}}^{1}\left(x_{i}^{1}, y_{i}^{1} ; \alpha\right) / D_{\mathrm{G}}^{1}\left(x_{i}^{1}, y_{i}^{1} ; \alpha\right)}= \\
& =\mathrm{TEC}_{\mathrm{G}}^{1, t}\left(x_{i}^{1}, y_{i}^{1}, x_{i}^{t}, y_{i}^{t} ; \alpha\right) \cdot \operatorname{SEC}_{\mathrm{G}}^{1, t}\left(x_{i}^{1}, y_{i}^{1}, x_{i}^{t}, y_{i}^{t} ; \alpha\right),
\end{aligned}
$$

where $\operatorname{TEC}_{\mathrm{G}}^{1, t}\left(x_{i}^{1}, y_{i}^{1}, x_{i}^{t}, y_{i}^{t} ; \alpha\right)$ compares how a given unit varies its technical efficiency in time with regard to the best practice technology existing in the base and comparison periods. Recalling from the previous section the scale efficiency definition $\operatorname{SE}^{t}\left(x^{t}, y^{t} ; \alpha\right)=\operatorname{PE}^{t}\left(x^{t}, y^{t} ; \alpha\right) / \operatorname{TE}^{t}\left(x^{t}, y^{t} ; \alpha\right)=$ $\hat{D}_{\mathrm{G}}^{t}\left(x^{t}, y^{t} ; \alpha\right) / D_{\mathrm{G}}^{t}\left(x^{t}, y^{t} ; \alpha\right)$, the second term in the right hand side of (7), $\operatorname{SEC}_{\mathrm{G}}^{1, t}\left(x_{i}^{1}, y_{i}^{1}, x_{i}^{t}, y_{i}^{t} ; \alpha\right)$, captures the change in scale efficiency from the base to the comparison period and with regard to the highest productivity attained at the optimal reference scales of both benchmark technologies.

Considering the decomposition of potential technical change (6) and efficiency change (7), it is possible to present the extended decomposition of the MPI proposed by SWLZ (1998):

$$
\begin{aligned}
\hat{\mathrm{M}}_{\mathrm{G}}^{1}\left(x_{i}^{1}, y_{i}^{1}, x_{i}^{t}, y_{i}^{t} ; \alpha\right)= & \frac{D_{\mathrm{G}}^{1}\left(x_{i}^{t}, y_{i}^{t} ; \alpha\right)}{D_{\mathrm{G}}^{t}\left(x_{i}^{t}, y_{i}^{t} ; \alpha\right)} \cdot \frac{\hat{D}_{\mathrm{G}}^{1}\left(x_{i}^{t}, y_{i}^{t} ; \alpha\right) / D_{\mathrm{G}}^{1}\left(x_{i}^{t}, y_{i}^{t} ; \alpha\right)}{\hat{D}_{\mathrm{G}}^{t}\left(x_{i}^{t}, y_{i}^{t} ; \alpha\right) / D_{\mathrm{G}}^{t}\left(x_{i}^{t}, y_{i}^{t} ; \alpha\right)}= \\
= & \frac{D_{\mathrm{G}}^{t}\left(x_{i}^{t}, y_{i}^{t} ; \alpha\right)}{D_{\mathrm{G}}^{1}\left(x_{i}^{1}, y_{i}^{1} ; \alpha\right)} \cdot \frac{\hat{D}_{\mathrm{G}}^{t}\left(x_{i}^{t}, y_{i}^{t} ; \alpha\right) / D_{\mathrm{G}}^{t}\left(x_{i}^{t}, y_{i}^{t} ; \alpha\right)}{\hat{D}_{\mathrm{G}}^{1}\left(x_{i}^{1}, y_{i}^{1} ; \alpha\right) / D_{\mathrm{G}}^{1}\left(x_{i}^{1}, y_{i}^{1} ; \alpha\right)}= \\
= & \operatorname{TC}_{\mathrm{G}}^{1, t}\left(x_{i}^{t}, y_{i}^{t} ; \alpha\right) \cdot \mathrm{STC}_{\mathrm{G}}^{1, t}\left(x_{i}^{t}, y_{i}^{t} ; \alpha\right) . \\
& \cdot \operatorname{TEC}_{\mathrm{G}}^{1, t}\left(x_{i}^{1}, y_{i}^{1}, x_{i}^{t}, y_{i}^{t} ; \alpha\right) \cdot \operatorname{SEC}_{\mathrm{G}}^{1, t}\left(x_{i}^{1}, y_{i}^{1}, x_{i}^{t}, y_{i}^{t} ; \alpha\right) .
\end{aligned}
$$




\subsection{Alternative decompositions of the MPI}

From the previous formulation we can obtain the alternative decompositions of the MPI that have been proposed in the literature. We depart from the definition of the scale efficiency change in (7), which can be decomposed in the following terms:

$$
\begin{aligned}
\operatorname{SEC}_{\mathrm{G}}^{1, t}\left(x_{i}^{1}, y_{i}^{1}, x_{i}^{t}, y_{i}^{t} ; \alpha\right) & =\frac{\hat{D}_{\mathrm{G}}^{1}\left(x_{i}^{t}, y_{i}^{t} ; \alpha\right) / D_{\mathrm{G}}^{1}\left(x_{i}^{t}, y_{i}^{t} ; \alpha\right)}{\hat{D}_{\mathrm{G}}^{1}\left(x_{i}^{1}, y_{i}^{1} ; \alpha\right) / D_{\mathrm{G}}^{1}\left(x_{i}^{1}, y_{i}^{1} ; \alpha\right)} / \frac{\hat{D}_{\mathrm{G}}^{1}\left(x_{i}^{t}, y_{i}^{t} ; \alpha\right) / D_{\mathrm{G}}^{1}\left(x_{i}^{t}, y_{i}^{t} ; \alpha\right)}{\hat{D}_{\mathrm{G}}^{t}\left(x_{i}^{t}, y_{i}^{t} ; \alpha\right) / D_{\mathrm{G}}^{t}\left(x_{i}^{t}, y_{i}^{t} ; \alpha\right)}= \\
& =\operatorname{RTS}_{\mathrm{G}}^{1}\left(x_{i}^{1}, y_{i}^{1}, x_{i}^{t}, y_{i}^{t} ; \alpha\right) / \operatorname{STC}_{\mathrm{G}}^{1, t}\left(x_{i}^{t}, y_{i}^{t} ; \alpha\right),
\end{aligned}
$$

where the new term $\operatorname{RTS}_{\mathrm{G}}^{1}\left(x_{i}^{1}, y_{i}^{1}, x_{i}^{t}, y_{i}^{t} ; \alpha\right)$ represents productivity variations coming from a change in the scale of the evaluated unit with respect to the base technology, i.e. returns to scale. $\operatorname{RTS}_{\mathrm{G}}^{1}\left(x_{i}^{1}, y_{i}^{1}, x_{i}^{t}, y_{i}^{t} ; \alpha\right)$ corresponds to what RD (1997) initially referred to as scale efficiency change, as well as Grifell-Tatjé and Lovell (1999) and Balk (2001). However, the structure of this term clearly differs from the one in the first line of (7), as the latter uses a single period technology while scale efficiency change compares scale efficiency with regard to own period technologies, i.e. how the unit moves toward or away from optimal scale in both periods.

By recalling the technical change and technical efficiency change terms already introduced in (6) and (9) we obtain the decomposition proposed by RD (1997):

$$
\begin{aligned}
\hat{\mathrm{M}}_{\mathrm{G}}^{1}\left(x_{i}^{1}, y_{i}^{1}, x_{i}^{t}, y_{i}^{t} ; \alpha\right) & =\frac{D_{\mathrm{G}}^{1}\left(x_{i}^{t}, y_{i}^{t} ; \alpha\right)}{D_{\mathrm{G}}^{t}\left(x_{i}^{t}, y_{i}^{t} ; \alpha\right)} \cdot \frac{D_{\mathrm{G}}^{t}\left(x_{i}^{t}, y_{i}^{t} ; \alpha\right)}{D_{\mathrm{G}}^{1}\left(x_{i}^{1}, y_{i}^{1} ; \alpha\right)} \cdot \frac{\hat{D}_{\mathrm{G}}^{1}\left(x_{i}^{t}, y_{i}^{t} ; \alpha\right) / D_{\mathrm{G}}^{1}\left(x_{i}^{t}, y_{i}^{t} ; \alpha\right)}{\hat{D}_{\mathrm{G}}^{1}\left(x_{i}^{1}, y_{i}^{1} ; \alpha\right) / D_{\mathrm{G}}^{1}\left(x_{i}^{1}, y_{i}^{1} ; \alpha\right)}= \\
& =\operatorname{TC}_{\mathrm{G}}^{1, t}\left(x_{i}^{t}, y_{i}^{t} ; \alpha\right) \cdot \operatorname{TEC}_{\mathrm{G}}^{1, t}\left(x_{i}^{1}, y_{i}^{1}, x_{i}^{t}, y_{i}^{t} ; \alpha\right) \cdot \operatorname{RTS}_{\mathrm{G}}^{1}\left(x_{i}^{1}, y_{i}^{1}, x_{i}^{t}, y_{i}^{t} ; \alpha\right) .
\end{aligned}
$$

If $\operatorname{RTS}_{\mathrm{G}}^{1}\left(x_{i}^{1}, y_{i}^{1}, x_{i}^{t}, y_{i}^{t} ; \alpha\right)>1$, the unit improves its performance on a scale basis with regard to the base period productivity benchmark by exploiting increasing returns to scale and getting closer to the MPSS. Contrarily, $\operatorname{RTS}_{\mathrm{G}}^{1}\left(x_{i}^{1}, y_{i}^{1}, x_{i}^{t}, y_{i}^{t} ; \alpha\right)<1$ indicates that input change carries decreasing returns to scale and the unit is moving away from optimal scale. Finally, when $\operatorname{RTS}_{\mathrm{G}}^{1}\left(x_{i}^{1}, y_{i}^{1}, x_{i}^{t}, y_{i}^{t} ; \alpha\right)$ $=1$, the unit does not profit (endure) from scale economies (diseconomies) as when constant returns to scale prevail over the input-output scale range.

Finally, the initial decomposition of the MPI introduced by FGNZ (1994) departs from (7) by decomposing the efficiency change component: 


$$
\begin{aligned}
\hat{\mathrm{M}}_{\mathrm{G}}^{1}\left(x_{i}^{1}, y_{i}^{1}, x_{i}^{t}, y_{i}^{t} ; \alpha\right) & =\frac{\hat{D}_{\mathrm{G}}^{1}\left(x_{i}^{t}, y_{i}^{t} ; \alpha\right)}{\hat{D}_{\mathrm{G}}^{t}\left(x_{i}^{t}, y_{i}^{t} ; \alpha\right)} \cdot \frac{D_{\mathrm{G}}^{t}\left(x_{i}^{t}, y_{i}^{t} ; \alpha\right)}{D_{\mathrm{G}}^{1}\left(x_{i}^{1}, y_{i}^{1} ; \alpha\right)} \cdot \frac{\hat{D}_{\mathrm{G}}^{t}\left(x_{i}^{t}, y_{i}^{t} ; \alpha\right) / D_{\mathrm{G}}^{t}\left(x_{i}^{t}, y_{i}^{t} ; \alpha\right)}{\hat{D}_{\mathrm{G}}^{1}\left(x_{i}^{1}, y_{i}^{1} ; \alpha\right) / D_{\mathrm{G}}^{1}\left(x_{i}^{1}, y_{i}^{1} ; \alpha\right)}= \\
& =\operatorname{PTC}_{\mathrm{G}}^{1, t}\left(x_{i}^{t}, y_{i}^{t} ; \alpha\right) \cdot \operatorname{TEC}_{\mathrm{G}}^{1, t}\left(x_{i}^{1}, y_{i}^{1}, x_{i}^{t}, y_{i}^{t} ; \alpha\right) \cdot \operatorname{SEC}_{\mathrm{G}}^{1}\left(x_{i}^{1}, y_{i}^{1}, x_{i}^{t}, y_{i}^{t} ; \alpha\right) .
\end{aligned}
$$

It is important to remark that asking for an economically meaningful decomposition of the MPI is equivalent to discard any proposal whose terms cannot be consistently interpreted in a theory of production context. In this respect, while (8), (10) and (11) decompose in terms which have a clear interpretation, we observe that some of them can be combined in different but intelligible ways to produce the same MPI result. However, by choosing any of the two latter decompositions one sacrifices some information regarding technical and scale changes, even if both proposals are interrelated. In fact, from (6) $\operatorname{PTC}_{\mathrm{G}}^{1, t}\left(x_{i}^{t}, y_{i}^{t} ; \alpha\right)=\operatorname{TC}_{\mathrm{G}}^{1, t}\left(x_{i}^{t}, y_{i}^{t} ; \alpha\right) \cdot \operatorname{STC}_{\mathrm{G}}^{1, t}\left(x_{i}^{t}, y_{i}^{t} ; \alpha\right)$, and from (9) $\operatorname{SEC}_{\mathrm{G}}^{1}\left(x_{i}^{1}, y_{i}^{1}, x_{i}^{t}, y_{i}^{t} ; \alpha\right)=\operatorname{RTS}_{\mathrm{G}}^{1}\left(x_{i}^{1}, y_{i}^{1}, x_{i}^{t}, y_{i}^{t} ; \alpha\right) / \operatorname{STC}_{\mathrm{G}}^{1, t}\left(x_{i}^{t}, y_{i}^{t} ; \alpha\right)$. Therefore, the scale bias of technical change $\operatorname{STC}_{\mathrm{G}}^{1, t}\left(x_{i}^{t}, y_{i}^{t} ; \alpha\right)$ represents the cornerstone that links both decompositions, rendering possible a complete characterization of productivity change both from a technological - best practice - and efficiency perspective. Including this term in the MPI decomposition allows immediate access to all components that have been proposed in the literature.

As a result, Zofío (2007) argues in favor of the enhanced decomposition (8) by SWLZ (1998) as it is the most comprehensive by considering all the terms in which previous proposals decompose and can be easily recovered from-i.e. it provides the "building blocks" of any decomposition found in the MPI literature with regards to the contribution that scale change makes to productivity change.

\section{Empirical Implementation by Means of the Activity Analysis, DEA}

In this section we illustrate how to undertake the MPI analysis, which will allow us to determine the sources of productivity growth within the SFTP. In doing so, we rely on non-parametric Data Envelopment Analysis (DEA) techniques (Bonaccorsi and Daraio 2005; Guan and Wand 2004). This approach to efficiency and productivity measurement approximates the true but unknown technology by means of piecewise linear combinations of the observed data, which constitute a multidimensional production frontier -see Cooper et al. (2000) for an introduction to DEA within a production theory context. The DEA piecewise linear approximation of the technology- including its constant returns to scale characterization, is given by:

$$
\hat{\mathrm{T}}^{t}=\left\{(x, y): \sum_{i=1}^{\mathrm{I}} \mathrm{z}_{i}^{t} \mathrm{x}_{i n}^{t} \leq \mathrm{x}_{n}^{t}, n=1, \ldots, \mathrm{N} ; \sum_{i=1}^{\mathrm{I}} \mathrm{z}_{i}^{t} \mathrm{y}_{i m}^{t} \geq \mathrm{y}_{m}^{t}, m=1, \ldots, \mathrm{M} ; \mathrm{z}_{i}^{t} \geq 0, i=1, \ldots, \mathrm{I}\right\},
$$

where $z^{t}$ is a intensity vector whose values determine the linear combinations or facets which define 
the production frontier.

Our first program deals with the empirical implementation of the generalized distance function $\mathrm{D}_{\mathrm{G}}^{t}\left(x^{t}, y^{t} ; \alpha\right)$ representing technical efficiency. Specifically, to calculate this economic performance measure for any research unit $i$ ' we follow Zofio and Prieto (2006) and solve the following linear programming problem:

$D_{\mathrm{G}}^{t}\left(x_{i^{\prime}}^{t}, y_{i^{\prime}}^{t} ; \alpha\right)=\min _{\delta, z^{t}} \delta$

s.t.

$$
\begin{aligned}
& \sum_{i=1}^{\mathrm{I}} \mathrm{z}_{i}^{t} \mathrm{x}_{i n} \leq x_{i^{\prime} n}^{t} \delta^{1-\alpha}, \quad n=1, \ldots, \mathrm{N}, \\
& \sum_{i=1}^{\mathrm{I}} \mathrm{z}_{i}^{t} \mathrm{y}_{i m} \geq \mathrm{y}_{i^{\prime} m}^{t} / \delta^{\alpha}, \quad m=1, \ldots, \mathrm{M}, \\
& \sum_{i=1}^{\mathrm{I}} \mathrm{z}_{i}^{t}=1, \quad z^{t} \in \Re_{+}^{\mathrm{I}},
\end{aligned}
$$

The mix-period generalized productive efficiency of process $i$ ' observed in the comparison period with respect to the base period technology can be obtained by modifying (13) and solving for: $D_{\mathrm{G}}^{1}\left(x_{i^{t}}^{t}, y_{i^{\prime}}^{t} ; \alpha\right)=\min _{\delta, z_{i}^{1}} \delta$

s.t.

$$
\begin{aligned}
& \sum_{i=1}^{\mathrm{I}} \mathrm{z}_{i}^{1} \mathrm{x}_{i n}^{1} \leq \mathrm{x}_{i^{\prime} n}^{t} \delta^{1-\alpha}, \quad n=1, \ldots, \mathrm{N}, \\
& \sum_{i=1}^{\mathrm{I}} \mathrm{z}_{i}^{1} \mathrm{y}_{i m}^{1} \geq \mathrm{y}_{i^{\prime} m}^{t} / \delta^{\alpha}, \quad m=1, \ldots, \mathrm{M}, \\
& \sum_{i=1}^{\mathrm{I}} \mathrm{z}_{i}^{1}=1, \quad z^{1} \in \mathfrak{R}_{+}^{\mathrm{I}} .
\end{aligned}
$$

In both cases while the constant returns to scale generalized distance functions $\hat{D}_{\mathrm{G}}^{t}\left(x_{i}^{t}, y_{i}^{t} ; \alpha\right)$ and $\hat{D}_{\mathrm{G}}^{1}\left(x_{i}^{t}, y_{i}^{t} ; \alpha\right)$ - representing productive efficiency and comprising technical and scale efficiency, can be calculated solving for the same problems but dropping the convexity constraint $\sum_{i=1}^{\mathrm{I}} z_{i}^{t}=1$. Therefore the scale efficiency term $\operatorname{SE}^{t}\left(x^{t}, y^{t} ; \alpha\right)=\operatorname{PE}^{t}\left(x^{t}, y^{t} ; \alpha\right) \quad / \quad \operatorname{TE}^{t}\left(x^{t}, y^{t} ; \alpha\right)=$ $\hat{D}_{\mathrm{G}}^{t}\left(x^{t}, y^{t} ; \alpha\right) / D_{\mathrm{G}}^{t}\left(x^{t}, y^{t} ; \alpha\right)$ - and analogously for the based period technology, is the result of dividing the solution obtained when solving (13) and (14) by their constant returns to scale counterparts. All these programs allow the empirical implementation of the proposed productivity change analysis, rendering possible to decompose the MPI into the alternative terms already described.

\section{Results}

We constructed a data base including inputs and outputs provided to and generated by the 
research units participating in R\&D projects financed by the SFTP between 1988 and 1999. We conduct our analysis at the micro level. Following Olazarán et al. (2004), we do not consider the host public research centers as the decision making unit, but the research groups operating within them. This implies that different research units operating in the same center can participate in the program, and therefore are individually evaluated. Our target Decision Making Units (DMUs) include thus research units receiving financial and human capital inputs from the Spanish Central Administration to promote applied research within the SFTP. From an institutional perspective they belong to the Spanish National Research Council (CSIC). Due to the large proportion of R\&D projects obtained by CSIC research groups in the SFTP and the homogeneity of CSIC centers in terms of internal structure, institutional framework, research behavior and other contextual variables-most notably the absence of teaching duties — we have restricted our analysis to these types of research groups. By focusing on a smaller, but nevertheless homogenous and quite representative set of research groups, we considered that the dynamic evaluation of the SFTP would provide more conclusive results.

Data were gathered from the central administration body responsible for the project management—Dirección General de Enseñanza Superior e Investigación Científica. For the purposes of our study we focus on the role of R\&D projects in terms of financial and human capital inputs and three categories of outputs jointly representing a multidimensional output mix, namely training $(\mathrm{PhD}$ dissertations and trained scientific personnel), science-technology outputs (international articles and patents), and socio-economic outputs (bilateral R\&D contracts with firms).

The time period under study, 1988-1999, comprises the first three Spanish R\&D Plans- each covering a period of four years. However, as R\&D projects within the SFTP may last up to three years (CICYT 1987; Jiménez-Sáez 2005) we followed the same rationale in our analysis. Hence, our analysis is split into four periods, covering the natural periodicity length of R\&D projects: $1^{\text {st }}$ period: $1988-1990 ; 2^{\text {nd }}: 1991-1993 ; 3^{\text {rd }}: 1994-1996$; and $4^{\text {th }}: 1997-1999{ }^{6}$ Table 1 summarizes the variables used in the analysis, classified by input and output categories, their inter-periodical change rate, as well as the overall change rate over the entire time span.

[Table 1 approximately here]

Both the number of personnel and overall budget devoted to the SFTP decline markedly from the first to the last period (1997-1999/1988-1990), as well as in consecutive periods. From an output perspective, there is a marked growth in the number of $R \& D$ contracts signed between research units and private firms to promote joint partnerships leading to practical innovations $(166.5 \%$ when

\footnotetext{
${ }^{6}$ We are aware that a three-year periodicity may question the contemporaneous nature of the inputs employed and outputs attained since publications, patents and so on may have a longer time lag. To test the robustness of our results we have replicated all the calculations taking as output variables the-moving-average of the outputs observed in periods $t$ and $t+1$, and find that efficiency and productivity trends, as well as raking positions do not
} 
accounting for the change in the whole period). This remarkable increase suggests that the Spanish public research bodies are contributing extensively to the articulation of the SFIS (García-Martínez and Briz 2000). ${ }^{7}$ In terms of the output variables related to training, while the number of trained people shows a noticeable increase (33.2\%) from 1988-1990 to 1997-1999, the number of doctoral theses decreases by $36.5 \%$. The remaining variables representing S\&T outputs, both number of international papers and registered patents show positive values (40.3\% and $28.9 \%$ respectively). Summing up, with decreasing input variables and increasing output variables - except for Ph.D. theses, it is expected that research productivity growth is to be observed throughout the period.

\subsection{Productivity change within the SFTP}

Jiménez-Sáez et al. (2011) perform a DEA efficiency analysis to test to what extent CSIC research units are able to make efficient use of these diminishing budgets, and whether their traditional mode I research behavior, based on the attainment of pure scientific-technological results, is changing towards mode II. This mode II includes additional results that involve relationships with other agents, such as embedding personnel of firms within the units to train it, as well as bilateral R\&D contracts with firms, representative both of actions contributing to the articulation of an IS. Based on the profile of the different research groups, these authors propose a taxonomy of the efficient research units depending on their research strategies, which can be divided into: (i) comprehensive, (ii) partial, (iii) specialized and (iv) "shooting stars". Comprehensive groups perform an efficient multidimensional research strategy by producing all outputs and have an in depth knowledge of the SFIS. Partial research units represent the largest group comprising those observations whose activities are directed towards the two output dimensions that characterize scientific knowledge production in mode I, i.e. training and S\&T variables. Specialized groups are those research units that are consistently efficient by focusing on either S\&T variables or socio-economic goals related to profitable bilateral contracts with interest in particular research actions. Finally, "shooting stars" describes those efficient research units that sporadically participate in the SFTP with the objective of achieving a particular goal (i.e. accomplishing a specific project, signing a bilateral contract with a firm, etc.), but are not able to raise funds within the SFTP consistently in more than one period. ${ }^{8}$ We consider this typology when assessing the overall productivity growth of the efficient research units, examine the sources contributing to its increase, as shown in sections 5 and 6 , and highlight the most relevant trends followed by each of these groups.

The mean growth rates for all periods of the cumulated MPI are presented in Table 2, sorted

\footnotetext{
differ significantly.

${ }^{7}$ We consider R\&D contracts as an output because it is normally the outcome of a demonstrated research activity-successful enough to convince private firms about the utility and profitability of the applied research they are co-financing. Therefore, when comparing the efficiency and productivity of research groups it must be considered as an outcome of the group's trajectories.

${ }^{8}$ Therefore it is not possible to study productivity change for these efficient units, as well as any other inefficient
} 
by their (in)efficiency status and group typology: comprehensive, partial and specialized (values for the individual units are reported in Annex 1). ${ }^{9}$ Calculating average inter-periodical productivity growth rates is necessary so as to render comparable the productivity change of units participating in different number of periods, i.e. not all the CSIC research units included in the analysis participate in the four sub-periods comprising the whole time length under study. Considering the whole period of time, if we relate our results to those presented by Jiménez-Sáez (2004) we can conclude that research groups leading productivity gains have only captured a small proportion of the SFTP financial support (less than 30\%), while they have been engaged in the generation of a larger proportion of research results in any category (more than $40 \%$ of results).

[Table 2 approximately here]

Malmquist productivity change within the SFTP increased inter-periodically by $19.3 \%=$ $(1.193-1)^{*} 100$. The main driver of productivity growth is the change in the technology led by the efficient units operating at the most productive scale sizes, MPSSs, as technical change $\mathrm{TC}_{\mathrm{G}}^{1, t}$-i.e. the upward shift in the production frontier presents a $15.5 \%$ annual increase. Decomposing PTC ${ }_{\mathrm{G}}^{1, t}$ into its two sources, it is the shift in the production frontier allowing for variable returns to scale $\mathrm{TC}_{\mathrm{G}}^{1, t}$ what brings higher gains, 23.5\% - this measure can be interpreted as the frontier shift for the average output-input scales corresponding to each group. The remaining term, $\mathrm{STC}_{G}^{1, t}$ shows that productivity change at those average output-input scales exceeds that observed at the MPSSs by $4.7 \%$, and therefore technical change presents a bias in favor of the average productive scale when compared to that observed at the optimal ones. Productivity growth is barely boosted by efficiency change, $\mathrm{EC}_{\mathrm{G}}^{1, t}=$ $\mathrm{TEC}_{\mathrm{G}}^{1, t} \cdot \mathrm{SEC}_{\mathrm{G}}^{1, t}$-eq. (6) - as it contributes with a meager $2.6 \%$ increase, i.e. $1.026=(1.017 \cdot 1.009)-1$. Furthermore, technical change $\mathrm{TEC}_{\mathrm{G}}^{1, t}$ at the mean output-inputs scales amounts $1.7 \%$ per year, while $\mathrm{SEC}_{\mathrm{G}}^{1, t}$ stays at $0.9 \%$. From these results we conclude that, in relative terms, there is not a relevant and generalized catch-up process within the SFTP according to which inefficient research groups would converge toward the efficient frontier by adopting the best practice research strategies and behavior of the leading units, resulting in a slow rate of convergence. Finally, the last source of productivity growth corresponding to the contribution that returns to scale $\operatorname{RTS}_{\mathrm{G}}^{1, t}$ shows that changes in the output-input size carry decreasing returns to scale resulting in productivity decline. We remark that the relative contribution of these terms to productivity change is similar across all groups of research

unit participating in the SFTP in a single period.

${ }^{9}$ Note that in Table 2 we present mean values of the Malmquist indices and the different terms in which it decomposes; therefore, multiplying the values reported in Table 2 will not normally result in their aggregates. However, this multiplicative nature of the Malmquist index and its components is preserved in Annex 1, where 
units, either efficient or inefficient, as well as when sorting the former according to the previously discussed categories, i.e. as previously discussed the major source of productivity growth corresponds in every group to $\mathrm{TC}_{\mathrm{G}}^{1, t}$ while scale efficiency play a very limited role.

Virtually all productivity growth is attributable to technical change TC, since it is the main driver of PTC growth, while efficiency change barely contributes to the increment in the Malmquist index. For this reason we depict in figure 1 the connection between these two measures for each individual research group classified according to efficiency status-inefficient and efficient (sorted by group category), and whose size is proportional to the average of funding throughout the four periods. The correlation coefficient for the most comprehensive units 0.47 is clearly influenced by IFI-05 that exhibits a Malmquist index of 3.130, and would be statistically significant and rather high, 0.760 if this particular unit were excluded. ${ }^{10}$

[Figure 1 approximately here]

We focus now on the distribution of the inter-periodical cumulated productivity growth. Table 3 presents the Malmquist values for selected ranges - see figure 1 . There we observe that just 10 research units exceed a $40 \%$ increase in productivity growth (20\% of all units participating in the SFTP), while the bulk of the research units, 29 (58\%), show productivity growths under $40 \%$. Interestingly, 11 research units (the remaining $22 \%$ ) experience productivity decreases, mainly as a result of losses in technical and scale efficiency, whose average values decrease by $-9.8 \%$ and $-3.9 \%$ respectively, as the average potential productivity change available to them increases by $4.6 \%$. Looking at the different terms contributing to productivity growth we observe that for the whole group of units attaining productivity change over $20 \%$, all terms make a positive contribution to productivity growth - recall that STC $\underset{\mathrm{G}}{1, t}<1$ has a positive interpretation, since it implies that the most productive scales converge in size to the mean output-input scale of the comparison units, therefore presenting a bias in favour of those grouped in each productivity range.

[Table 3 approximately here]

\subsection{Comparing productivity trends across efficient groups.}

So far we have discussed the productivity trends of research units from a general perspective

\footnotetext{
all terms can be obtained by direct multiplication.

${ }^{10}$ However, anticipating our discussion on individual leading units, we stress that the remarkable productivity change value of IFI-05 cannot be recognized as an outlier resulting from data measurement errors, but as the outcome of an outstanding performance. This unit is able to increase outputs while reducing inputs resulting in a productivity growth $\hat{\mathrm{M}}_{\mathrm{G}}^{1, t}=3.130$ that can be mostly explained in terms of a remarkable scale efficiency change $\mathrm{SEC}_{\mathrm{G}}^{1, t}=1.566$, jointly with a substantial technological progress equal to $\mathrm{TC}_{\mathrm{G}}^{1, t}=1.491$.
} 
and focusing on their (in)efficiency status, as well as the their technological and efficiency change drivers according to the alternative decompositions. However, more insight on best research practices can be gained by comparing the mean values of the MPI and its components across the different categories of efficient research units- Table 2. The units leading productivity growth are the comprehensive ones with an outstanding $41.7 \%$ increase, followed by units ascribed to the partial groups (25.6\%), while units adopting a specialized research strategy in the output dimension exhibit some productivity decline (20.3\%). These are important results suggesting that pursuing a comprehensive research activity results in higher productivity growth than relying on a specialized strategy focused on single and very specific activities such as patents and publications (S\&T outputs) or bilateral joint ventures with private firms ( $R \& D$ contracts). The rationale for this differential can be found in inter-product complementarities, and it can be argued that the usual reasons behind the existence of economies of scope, associated to common and shareable inputs in the production of joint multilateral outputs - already found by Kao (2008) in higher education, are present in research activities within the SFIS. This is particularly relevant from a policy oriented perspective since the burden of the articulation of the SFIS finally rests upon the comprehensive units, and therefore provides evidence supporting funding strategies that favour units adopting a holistic research vision.

We conclude then that on average comprehensive research units producing a balanced output mix without neglecting any of the research dimensions (training, S\&T and socio-economic) achieve higher productivity increases than their smaller specialized counterparts focusing on the production of a single output dimension -normally S\&T outputs or R\&D contracts-. Moreover, focusing in the FGNZ decomposition (1994), we note that the mean value of potential technical change $\mathrm{PTC}_{\mathrm{G}}^{1, t}$ for the comprehensive group (25.1\%) exceeds that for all research units (15.5\%) as well as the efficient units (21.5\%), confirming that these units drive the production frontier upwards. Additionally, as the research units classified in the efficient groups are those that define the production frontier in at least one period, efficiency increases or decreases cannot be large in magnitude - when they are efficient in all periods from a technical and scale perspective (IG-02, IF-03, IQOG-02 and IIM-01 in our study). Then $\mathrm{EC}_{\mathrm{G}}^{1, t}=\mathrm{TEC}_{\mathrm{G}}^{1, t} \cdot \mathrm{SEC}_{\mathrm{G}}^{1, t}=1$, and productivity growth cannot have origin in the catching-up process associated to efficiency increases. ${ }^{11}$ This is illustrated in Figure 2 showing the relationship between the mean efficiency achieved by each research unit and its inter-periodical productivity change. It can be observed that the four units fully efficient in all periods do not manage to achieve high levels of productivity growth as they cannot benefit from efficiency improvements. This is a logical conclusion, as these units are the main responsible for the expansion of the benchmark production frontier. ${ }^{12}$ Hence, if these units achieved higher levels of productivity change it would

\footnotetext{
${ }^{11}$ As in Table 1 we present the values associated to the Malmquist index referred to first base period - satisfying the circularity test, all it is required for $\mathrm{EC}_{\mathrm{G}}^{1, t}=\mathrm{TEC}_{\mathrm{G}}^{1, t} \cdot \mathrm{SEC}_{\mathrm{G}}^{1, t}=1$ in Annex 1 is that research units are efficient in the base and last periods, regardless of their efficiency level in the in-between periods.

${ }^{12}$ Notice that potential productivity change does not have to be led by a single research unit as it is just the
} 
imply that the technological frontier is moving away rather rapidly, with the consequent loss of competitiveness for the remaining research units that would lag behind in their productivity change resulting in efficiency decreases. Zofío (2007) shows that the efficiency change experienced by a particular unit can be expressed as the ratio between its productivity change- Malmquist index-and the technical change of the fully efficient leading units, i.e. how a unit's productivity change compares to those of the benchmark units: $\mathrm{EC}_{\mathrm{G}}^{1, t}=\mathrm{TEC}_{\mathrm{G}}^{1, t} \cdot \mathrm{SEC}_{\mathrm{G}}^{1, t}=\mathrm{M}_{G}^{1, t} / \mathrm{PTC}_{\mathrm{G}}^{1, t}$. Therefore when $\mathrm{M}_{\mathrm{G}}^{1, t}<$ PTC $_{\mathrm{G}}^{1, t}, \mathrm{EC}_{\mathrm{G}}^{1, t}<1$, implying that since the evaluated unit is not able to follow the productivity increases of the best research units, it lags behind losing efficiency. Finally, figure 2 portraits one of the main conclusions of our research: fully efficient comprehensive units of a relatively large size lead productivity growth rates, while large units with a partial research orientation tend to be very inefficient and therefore cannot lead the expansion of the production frontier.

[Figure 2 approximately here]

\subsection{Productivity trends between periods}

We now discuss productivity growth trends between periods. To ease the interpretation we recall the formulation of the fixed-base adjacent period version of the MPI (Eq. 3), that can be decomposed in the same way as the MPI version relying on a constant reference period (Eq. 4). Table 4 shows mean values of productivity change by group categories. For all research units we observe that productivity grows at a steady rate over the four periods, with a slight decreasing trend in the Malmquist index from $80.9 \%$ between the first two periods to $54.8 \%$ between the last two. However, focusing on FGNZ's (1994) MPI decomposition we observe that the relative contributions corresponding to potential technical change $\mathrm{PTC}_{\mathrm{G}}^{1, t}$, and efficiency change $\mathrm{EC}_{\mathrm{G}}^{1, t}=\operatorname{TEC}_{\mathrm{G}}^{1, t} \cdot \mathrm{SEC}_{\mathrm{G}}^{1, t}$, greatly change across periods. While $\mathrm{PTC}_{\mathrm{G}}^{1, t}$ is the main source of productivity change between the first three periods, $\mathrm{TEC}_{\mathrm{G}}^{1, t}$ takes over between the last two, confirmed by the fact that technical change at the most productive scale sizes comes to a sudden halt: $\mathrm{PTC}_{\mathrm{G}}^{1, t}=1.090$, which favors a catching-up process where the follower inefficient units are able to converge toward the frontier by reducing their relative technical inefficiency, $\mathrm{TEC}_{\mathrm{G}}^{1, t}=1.584$, even if they are not able to approach the scale size of the most productive leading units, $\mathrm{SEC}_{\mathrm{G}}^{1, t}=0.982$. This is an expected result since the size of research units in terms of inputs (personnel and funding) and outputs (training, S\&T and socio-economic) remain stable over time - the mean value of these variables per research unit is unchanged over the four periods, except for bilateral contracts that triple in value. This implies that the alternative decompositions by RD (1997) and SWLZ (1998) exploring the role that returns to scale $\operatorname{RTS}_{G}^{1, t}$ and the 
scale bias of technical change $\mathrm{STC}_{\mathrm{G}}^{1, t}$ play in productivity change, also present the same relative small effects. Nevertheless we stress that scale efficiency improves between the second and third period by $15.1 \%$, since changes in the individual input and output sizes carry increasing returns to scale with respect to the reference optimal sizes, enhanced by the fact that the latter also change in favour of the research units - as argued when discussing $\mathrm{SEC}_{\mathrm{G}}^{1, t}=\mathrm{RTS}_{\mathrm{G}}^{1, t} / \mathrm{STC}_{\mathrm{G}}^{1, t}$ in section 5.

We complete this discussion on productivity trends by stating that this overall general description of productivity change for all research units is consistent with the opposing time patterns of the efficient and inefficient groups. In other words, when efficient units exhibit large technical change values, it is expected that inefficient units suffer from inefficiency increases as they are not able to keep up with their leading peers and therefore lag behind, e.g. taking as reference the RD (1997) and SWLZ (1998) decompositions, between the second and third periods mean technical change $\mathrm{TC}_{\mathrm{G}}^{1, t}$ in the efficient group increases by $115.3 \%=(2.153-1) \cdot 100$, and efficiency reduces by $29.3 \%=(1-$ $0.702)^{*} 100$ in the inefficient group. But from the third to the fourth period the contrary takes place. As efficient units push the frontier to a lesser extent, $43.8 \%$, this offers the possibility for the inefficient units to catch-up, and mean technical efficiency increases by $115.4 \%$ in this group. Therefore, the lower the technical change driven by the leading units, the larger the efficiency change (catch-up) term. Finally we note that among the different groups of efficient units, there is some heterogeneity, with comprehensive and specialized units leading technical change between the first and second periods, as well as between the third and fourth periods, while partial units take the lead between the second and third periods — with all the remaining terms behaving accordingly.

[Table 4 approximately here]

\subsection{Productivity trends of leading research units}

To identify best practice behavior in research productivity we discuss in depth the productivity trends of the leading units achieving remarkable average inter-periodical productivity growths over 50\%. In Annex 1 we find that among the efficient units, that achieving the highest growth is IFI-05 (213.0\%), categorized as comprehensive, followed by IATA-06 (specialized in S\&T) that reaches a $100.0 \%$, IF-01 (partially oriented in training and S\&T) with a $97.8 \%$ rate and, finally, IIM-01 (also categorized as comprehensive) that presents a $61.4 \%$ productivity increase.

The leading unit IFI-05 participated in the first two periods under study (1988-90 and 199193), and the main reasons for its outstanding productivity growth is the observed increase in the number of publications (no articles in the first period but four in the second), along with the enlargement observed in the bilateral R\&D contracts with private firms (from 5.787€ to $12.380 €$, respectively), and a reduction of $72.1 \%$ in the public funding obtained from the SFTP (45.397€ in the

which may be achieved by different units in each period. 
first period and $13.222 €$ in the second). Despite its small size (3 FTE personnel), it is remarkable how this unit managed to evolve from an inefficient specialized unit in the first period to an efficient comprehensive unit in the second period. In this scheme, the potential for productivity growth is enormous because IFI-05 can ripe the benefits of the technological change driven by the larger efficient units, while being able to catch-up with the frontier, i.e. $\hat{\mathrm{M}}_{G}^{1, t}>\mathrm{PTC}_{G}^{1, t}$ and therefore $\mathrm{EC}_{G}^{1, t}>1$ -Figure 2 presenting the relationship between mean efficiency and productivity change allow us to see the extent for potential efficiency improvements. Regrettably, this unit was not able to survive as a result of its rather small size, when compared to other comprehensive units leading productivity research in absolute terms. In addition, this small group has followed a collaborative strategy since an important proportion of their projects are carried out on demand with firms from the food industry. This strategy has proven difficult to survive since the leading agent of these projects is the firm and not the research group itself.

Contrarily to IFI-05, IATA-06 participated in the last two periods, being a specialized research group whose productivity growth is mainly due to the decreasing amount of inputs employed as the production of outputs was constant in time. This case also represents how small and young research groups try to emerge thanks to the institutional support of their first approved project, but individual researchers have to deal with contradicting incentives to promote in their careers, forcing them to focus on S\&T outputs - mainly publications, thereby withdrawing from the potential financial support offered by the SFTP and signing bilateral contracts with firms. This input trend is also observed for IF01 that participated in the SFTP in all four periods. It is considered as a partial research group because its outputs are mainly oriented towards producing training and $\mathrm{S} \& \mathrm{~T}$ results (publications and patents). The reason behind its remarkable productivity growth is the extreme reduction in the public funding obtained from the SFTP (from $81.557 €$ in 1988 to $15.025 €$ in 1997) as output production remains constant. Here we find a rather large research group whose leading researcher has devoted part of his time during the period considered in our study to management tasks within the SFTP. The absence of the research group's leader has resulted in a considerable reduction in funding. As regards to the story behind IIM-01, we note that this research unit participated intermittently in the first, second and fourth periods. On the input side it reduced the personnel devoted to participating in the SFTP from 3 FTE personnel in the first period to just 1 in the last period, while the funding awarded by the SFTP was also reduced from $85.283 €$ to $55.052 €$ respectively. This also reflects the relevance of projects in collaboration with firms as a result of previous academic research. On the output side IIM-01 doubled from 3 to 6 the people in training, and what is more spectacular, elevated from none to $120.064 €$ the funding obtained from private R\&D contracts with firms. As a setback, the number of publications fell from 12 to 5 over these years.

From this discussion we conclude that productivity increases are driven by very different trends in inputs and outputs variations and that successful stories in terms of efficiency and 
productivity growth within the SFTP does not always secures the consolidation of the group within the innovation system. Even if what counts in the end for productivity growth is that output change must be larger than input change, it can be shown that in many cases this relative growth is result of declining inputs trends rather that output increases. A situation that concerns $R \& D$ managers since the goals of the program -as stated in section 3-were to encourage scientific research, training as well as technological innovation and transfer, and this contribution to output growth is not always granted by remarkable productivity increases.

\section{Conclusions}

The SFTP, as other R\&D Programs within the Spanish R\&D plan, which are comparable to similar plans in developed countries, was designed to cover all the stages in the innovation process, offering possibilities for participation to a wide variety of agents, and fostering co-operation among them. Our goal is to propose an evaluation framework that allows R\&D managers to assess the efficiency and productivity performance of research units participating as well as to measure their contribution to the Spanish Food Innovation System. In this respect, ex-post evaluation methodologies are mainly focused on outputs/input ratios, results achieved, impacts and the like indicators with little concern on how those indicators were achieved over time. We offer an evaluation framework where research groups' dynamics are a key aspect of policy implementation and evaluation, becoming an input for policy-makers in the next policy generation. This enhanced evaluation framework seeds light on micro, meso and macro-level aspects of any policy, helping policy-makers to ground future changes in policy design based on the observed results and particular trajectories.

To show its practicality in strategic planning we draw several specific and practical conclusions that may constitute guidelines for research managers, and make the following policy recommendations:

i) Since the Spanish SFTP has exhibited an outstanding inter-periodical productivity growth with an average $19.3 \%$ increase every three years -around $6 \%$ yearly, we conclude that the implementation of the SFTP, and the particular allocation of (diminishing) inputs has been successful in general. However, this trend is not observed to the same extend across research units since our analysis unveils a high heterogeneity that can be discussed according to the typology of comprehensive, partial and specialized research units.

ii) Groups undertaking a comprehensive research should be promoted by the program as they prove themselves not only efficient in managing the scarce resources made available to them, but also capable of fostering research productivity growth while increasing their multidimensional output. Over the twelve year period this group increased its productivity by $41,7 \%$ on average, outgrowing the productivity rates of other groups of efficient units that, despite being more numerous, do not contribute to the same extent to the achievement of the goals of the SFTP because of their partial or specialized research orientation- these units in particular exhibit a productivity decline to the tune of 
$-5,5 \%$ ). Moreover, since comprehensive units rank high in terms of their efficiency levels (some of them being always efficient throughout the whole period) we confirm that the main source of this remarkable productivity growth is the expansion of the research frontier- technical change.

iii) R\&D policy managers should be worried about the fact that the higher share of the units decide for a partial research orientation, focusing their work solely on science and technology outputs (mainly articles published in international journals), rather than undertaking personnel training or signing bilateral $\mathrm{R} \& \mathrm{D}$ contracts with the private sector. The reason behind this narrow research orientation is that the promotion of their members is based by far on this criterion. This is particularly grave since most of the inefficient units follow this partially oriented research strategy. This suggests that the incentives of academics do not agree with those of the R\&D managers, and that research activities that contribute to a larger extent to the articulation of the Spanish Food Innovation System are prone to principal-agent problems that result in inefficient research practices.

iv) Looking at the average evolution in productivity growth for those units participating in the SFTP that start out from an inefficient situation, ours results confirm that they are not able to converge toward the production frontier, casting a shadow on their performance. On average they are able to attain productivity growth levels that barely match those of their efficient counterparts. This is rather unsatisfactory from a policy perspective because it implies that they are not able to profit from a catching-up process thereby reducing average inefficiency within the SFTP. One of the reasons why inefficiency levels remain constant over the period is that inefficient units are not able to converge toward the optimal production scale represented by the comprehensive units, whose size in terms of the amount of output and inputs is well above the average.

v) The analysis shows that large units undertaking a comprehensive research must constitute the benchmark peers against which all remaining units are confronted, and therefore their best practices should become the guidelines underlying the financial scheme of the program. Based on this conclusion we believe that a new financial line introduced in the announcement of the 2006 Spanish $\mathrm{R} \& \mathrm{D}$ plan (including the SFTP), reorienting some of the funding so as to promote the creation and consolidation of this kind of units, must be welcomed. The new line, known as "consolider", extends the duration of the average project form 3 to 5 years and grants an average budget of 1 million Euros. Nevertheless, to apply to this line, a minimum size must be met, i.e., it is required that a minimum of 5 units—with at least 4 researchers each—agree on a single proposal also contributing to the networking objective. Besides the general objectives of all programs, the declared goal of this line is to increase the competitiveness of Spanish research groups at international levels, e.g. the European framework program, by increasing the "critical mass" of research groups-i.e. creating large comprehensive units - that should translate into higher research productivity. ${ }^{13}$ In a sense this change in the R\&D

\footnotetext{
${ }^{13}$ In 2011, research proposals were evaluated using different criteria depending on their characteristics: i) the "consolider" line already described, ii) the general and conventional line that did not require a minimum size (i.e. using the criteria exiting until then) and iii) a line reserved to young researchers under 40 years old and whose
} 
plans acknowledges the pitfalls of the financial scheme existing until then. Since grants could not be awarded to large groups because there was not a particular financial line specifically aimed at promoting the consolidation of larger groups, most of the funding would end up in units carrying out a partial research orientation, whose results are less satisfactory as already discussed.

There are some limitations to this study which encourage further research efforts. One of these is the focus on a single national program which affects the degree to which our conclusions can be generalized to other research environments. That would allow policy-makers to benefit from the application of the conclusions obtained not only in countries where similar practices are implemented, but also on those where similar research group distributions are observed. In this sense, Schmoch and Schubert (2009), discuss the need to include a wide set of indicators when attributing excellence to the behavior of certain research units. We find that their conclusions are very much illustrated by our case study, where we also use a wide array of indicators.

Further work on our evaluation methodology is concerned with the actual combination of neoclassical methods into an evolutionary policy framework, also reflecting Lundvall et al.'s (2002) concern on how to link input/output analyses with evolutionary economics that will benefit the policy evaluation discipline. Besides, to lay additional bridges between the Neoclassical and Evolutionary realms we also suggest the addition of qualitative information into the quantitative framework that is already being developed so as critical aspects can be incorporated into the evaluation process that so far can hardly be included into a quantitative evaluation methodology (e.g. the concepts of strategic capital, social network capital, etc.) A first step would be to consider them as categorical variables within our quantitative DEA approach.

Finally, we consider that our study of the key features of research units exhibiting a best practice behavior associated to high efficiency and productivity levels shows the potential of the proposed Malmquist productivity change analysis as a valid methodology to undertake research performance evaluations and achieve the proposed policy-guidelines goal. The conclusions we draw are useful to policy and decision-makers when reorienting the policy based on a dynamic ex-post evaluation of research groups' performance, thereby allowing them to undertake a command and control strategic planning of the role that research groups should play within an articulated innovation system, so as to better contribute to its final goal of social wealth creation.

\section{Acknowledgements}

We are grateful to the participants and discussants at the EASST 2010 Conference (September 2nd4th, Trento, Italy) and the 1st Workshop on Efficiency and Productivity (October 7th-8th, 2010, Valencia, Spain) for their comments and suggestions.

proposal clearly departs from those of their supervisors. This segmentation of the financial scheme system guarantees that funds are allocated among researchers competing in the same category, as using one single set of criteria did not give managers the flexibility to finance large projects on a long term basis or ensure that enough 


\section{References}

Abbring, J.H., \& Heckman, J.J. (2008). Dynamic Policy Analysis. In L. Mátyás, \& P. Sevestre (Eds.), The Econometrics of Panel Data (3rd ed.) (pp. 795-863). Heidelberg: Springer-Verlag.

Acosta Ballesteros, J., Modrego Rico, A. (2001). Public financing of cooperative R\&D projects in Spain: the Concerted Projects under the National R\&D Plan. Research Policy, 30, 625-641.

Arbel, A. (1981). Policy evaluation in the dynamic input-output model. International Journal of Systems Science, 12, 255-260.

Arnold, E. (2004). Evaluation research and innovation policy: a systems world needs systems evaluations. Research Evaluation, 13, 3-17.

Arrow, J. K. (1962). Economic welfare and the allocation of resources for inventions. In R. Nelson (Ed.), The rate and direction of inventive activity: economic and social factor (pp. 609-625). Princeton: Princeton University Press and NBER.

Autio, E. (1997). New, technology-based firms in innovation networks symplectic and generative impacts. Research Policy, 26, 263-281.

Balk, B. (2001). Scale Efficiency and Productivity Change. Journal of Productivity Analysis, 15, 153183.

Balzat, M., Hanusch, H. (2004). Recent trends in the research on national innovation systems. Journal of Evolutionary Economics, 14, 197-210.

Berg, S. A., Førsund, F.R., Jansen, E.S. (1992). Malmquist Indices of Productivity Growth During the Deregulation of Norwegian Banking. Scandinavian Journal of Economics, 94, S211-S228.

Bergek, A., Carlsson, B., Lindmark, S., Rickne, A., Jacobsson, S. (2008). Analyzing the Functional Dynamics of Technological Innovation Systems: A Scheme of Analysis. Research Policy, 37, 407-429.

Bonaccorsi, A., Daraio, C. (2005). Exploring size and agglomeration effects on public research productivity. Scientometrics, 63(1), 87-120.

Buisseret, T. J., Cameron, H., Georghiou, L. (1995). What difference does it make? Additionality in the public support of $R \& D$ in large firms. International Journal of Technology Management, $10,587-600$.

Bustelo, M. (2006). The Potential Role of Standards and Guidelines in the Development of an Evaluation Culture in Spain. Evaluation, 12, 437-453.

Chavas, J.P., Cox, T.M. (1999). A Generalized Distance Function and the Analysis of Production Efficiency. Southern Economic Journal, 66, 295-318.

CICYT (1987). Programa Nacional de Tecnología de los Alimentos. Ministerio de Educación y Ciencia, Madrid.

CICYT (1988). Plan Nacional de Investigación Científica y Desarrollo Tecnológico 1988-1991. Ministerio de Educación y Ciencia, Secretaría de Estado de Universidades e Investigación,

funding would reach young researchers. 
Madrid.

Cooper, W.W., Seiford, L.M., \& Tone, K. (2000). Data Envelopment Analysis: A Comprehensive Text with Models, Applications, References and DEA-Software. Boston: Kluwer Academic Publishers.

David, P., Mowery, D., \& Steinmueller, W.E. (1994). Analyzing the economic payoffs from basic research. In D. Mowery (Ed.), Science and Technology Policy in Interdependent Economies (pp. 57-78). Boston: Kluwer Academic Publishers.

Dopfer, K., Foster, J., Potts, J. (2004). Micro-meso-macro. Journal of Evolutionary Economics, 14, 263-279.

Edquist, C., \& Hommen, L. (2008). Comparing National Systems of Innovation in Asia and Europe: Theory and Comparative Framework. In C. Edquist, L. Hommen (Eds.), Small Country Innovation Systems: Globalisation, Change and Policy in Asia and Europe (pp. 1-28). Cheltenham: Edward Elgar.

Farrell, M. (1957). The Measurement of Productive Efficiency. Journal of the Royal Statistical Society, Series A, General 120(3), 253-281.

Freeman, C. (1987). Technology Policy and Economic Performance: Lessons from Japan. London: Printer Publishers.

Färe, R., Grosskopf, S., Norris, M., Zhang, Z. (1994). Productivity Growth, Technical Progress, and Efficiency Change in Industrialized Countries. American Economic Review, 84, 66-83.

Førsund, F. R. (1993). Productivity Growth in Norwegian Ferries. In H.O. Fried, C.A.K. Lovell, \& S.S. Schmidt (Eds.), The Measurement of Productive Efficiency: Techniques and Applications (pp. 352-373). New York: Oxford University Press.

Førsund, F. R. (1997). The Malmquist Productivity Index, TFP and Scale. Working Paper, Department of Economics and Business Administration, University of Oslo.

García-Martínez, M., Briz, J. (2000). Innovation in the Spanish Food \& Drink Industry. International Food and Agribusiness Management Review, 3, 155-176.

Gibbons, M., Limoges, C., Nowotny, H., Schwartzman, S., Scott, P., \& Trow, M. (1994). The New Production of Knowledge: The Dynamics of Science and Research in Contemporary Societies. London: Sage Publications.

Grammatikopoulos, V., Kousteiios, A., Tsigilis, N., Theodorakis, Y. (2004). Applying dynamic evaluation approach in education. Studies in Educational Evaluation, 30, 255-263.

Grifell-Tatjé, E., Lovell, C.A.K. (1999). A Generalized Malmquist Productivity Index. Top, 7(1), 81101.

Grimpe, C., Sofka, W. (2007). Search Patterns and Absorptive Capacity: A Comparison of Low- and High-Technology Firms from Thirteen European Countries. Discussion Paper No 07-062, Centre for European Economic Research (ZEW), Mannheim, Germany.

Guan, J., Wang, J. (2004). Evaluation and interpretation of knowledge production efficiency. 
Scientometrics, 59(1), 131-155.

Hekkert, M.P., Suurs, R.A.A., Negro, S.O., Kuhlmann, S., Smits, R.E.H.M. (2007). Functions of innovation systems: A new approach for analysing technological change. Technological Forecasting and Social Change, 74, 413-432.

Jiménez-Sáez, F. (2005). Una Evaluación del Programa Nacional de Tecnología de Alimentos: análisis de la articulación fomentada sobre el Sistema Alimentario de Innovación en España. Ph.D. dissertation, Servicio de Publicaciones de la Universidad Politécnica de Valencia, Valencia.

Jiménez-Sáez, F., Zabala-Iturriagagoitia, J.M., Zofío, J.L., Castro-Martínez, E. (2011). Evaluating research efficiency within National R\&D Programmes. Research Policy, 40, 230-241.

Kao, C. (2008). Efficiency analysis of university departments: An empirical study. OMEGA, 36, 653664.

Kuhlmann, S. (2003). Evaluation of research and innovation policies: a discussion of trends with examples from Germany. International Journal of Technology Management, 26, 131-149.

Laitinen, E.K. (2002). A dynamic performance measurement system: evidence from small Finnish technology companies. Scandinavian Journal of Management, 18, 65-99.

Laranja, M., Uyarra, E., Flanagan, K. (2008). Policies for science, technology and innovation: Translating rationales into regional policies in a multi-level setting. Research Policy, 37(5), 823-835.

Lee, T-L., von Tunzelman, N. (2005). A dynamic analytic approach to national innovation systems: The IC industry in Taiwan. Research Policy, 34, 425-440.

Lipsey, R., \& Carlaw, K. (1998). A Structuralist Assessment of Technology Policies - Taking Schumpeter Seriously on Policy. Industry Canada Research Publications Program, Ottawa.

Lipsey, R., Carlaw, K., \& Bekar, C. (2005). Economic Transformations: General Purpose Technologies and Long Term Economic Growth. Oxford: Oxford University Press.

Lundvall, B.Å. (1992). National Systems of Innovation: Toward a Theory of Innovation and Interactive Learning. London: Printer Publishers.

Lundvall, B.Å., Johnson, B., Andersen, E.S., Dalum, B. (2002). National systems of production, innovation and competence building. Research Policy, 31, 213-231.

Markard, J., Truffer, B. (2008). Actor-oriented analysis of innovation systems: exploring micro-meso level linkages in the case of stationary fuel cells. Technology Analysis \& Strategic Management, 20, $443-464$.

Metcalfe, J.S. (2002). Equilibrium and Evolutionary Foundations of Competition and Technology Policy: new Perspectives on the Division of Labour and the Innovation Process. CRIC Working Papers series, University of Manchester.

Miettinen, R. (1999). The Riddle of Things. Activity Theory and Actor Network Theory as Approaches of Studying Innovations. Mind, Culture and Activity, 6, 170-195.

Molas-Gallart, J., Davies, A. (2006). Toward Theory-Led Evaluation: The Experience of European 
Science, Technology, and Innovation Policies. American Journal of Evaluation, 27, 64-82.

Mytelka, L.K., Smith, K. (2002). Policy learning and innovation theory: an interactive and co-evolving process. Research Policy, 31, 1467-1479.

Olazarán, M., Lavía, C., Otero, B. (2004). ¿Hacia una segunda transición en la ciencia? Política científica y grupos de investigación. Revista Española de Sociología, 4, 143-172.

Potts, J. (2007). The Innovation System \& Economic Evolution. Productivity Commission Submission, Public Support for Science \& Innovation, Productivity Commission, Camberra.

Ray. S., Desli, E. (1997). Productivity Growth, Technical Progress, and Efficiency Change in Industrialized Countries: Comment. American Economic Review, 87(5), 1033-1039.

Rip, A., Nederhof, A.J. (1986). Between Dirigism and Laissez-Faire: Effects of Implementing the Science Policy Priority for Biotechnology in the Netherlands. Research Policy, 15, 253-268.

Schmidt, E.K., Graversen, E.K., Langberg, K. (2003). Innovation and dynamics in public research environments in Denmark: a research-policy perspective. Science and Public Policy, 30, 107116.

Schmoch, U., Schubert, T. (2009). Sustainability of incentives for excellent research - The German case. Scientometrics, 81(1), 195-218.

Shephard, R. (1970). Theory of Cost and Production Functions. New Jersey: Princeton University Press.

Simar, L., \& Wilson, P.W. (1998). Productivity Growth in Industrialized Countries. Discussion Paper 9810, Universite Catholique de Louvain, Belgium.

Van Raan, A.F.J. (2000). R\&D evaluation at the beginning of the new century. Research Evaluation, 8, 81-86.

Zofio, J.L. (2007). Malmquist Productivity Index Decompositions: A Unifying Framework. Applied Economics, 39, 2371-2387.

Zofio, J.L., \& Lovell, C.A.K. (1998). Yet Another Malmquist Productivity index Decomposition. Working Paper, Department of Economics, University of Georgia, Athens, GA 30602, USA.

Zofio, J.L., Lovell, C.A.K. (2001). Graph Efficiency and Productivity Measures: An Application to US Agriculture. Applied Economics, 33(10), 1433-1442.

Zofio, J.L., Prieto, A.M. (2006). Return to Dollar, Generalized Distance Function and the Fisher Productivity Index. Spanish Economic Review, 8, 113-138. 
Figure 1.- Distribution of average inter-periodical cumulated change in $\operatorname{PTC}_{G}^{1, t}$ and $\mathrm{M}_{G}^{1, t}$ by efficiency status and size.

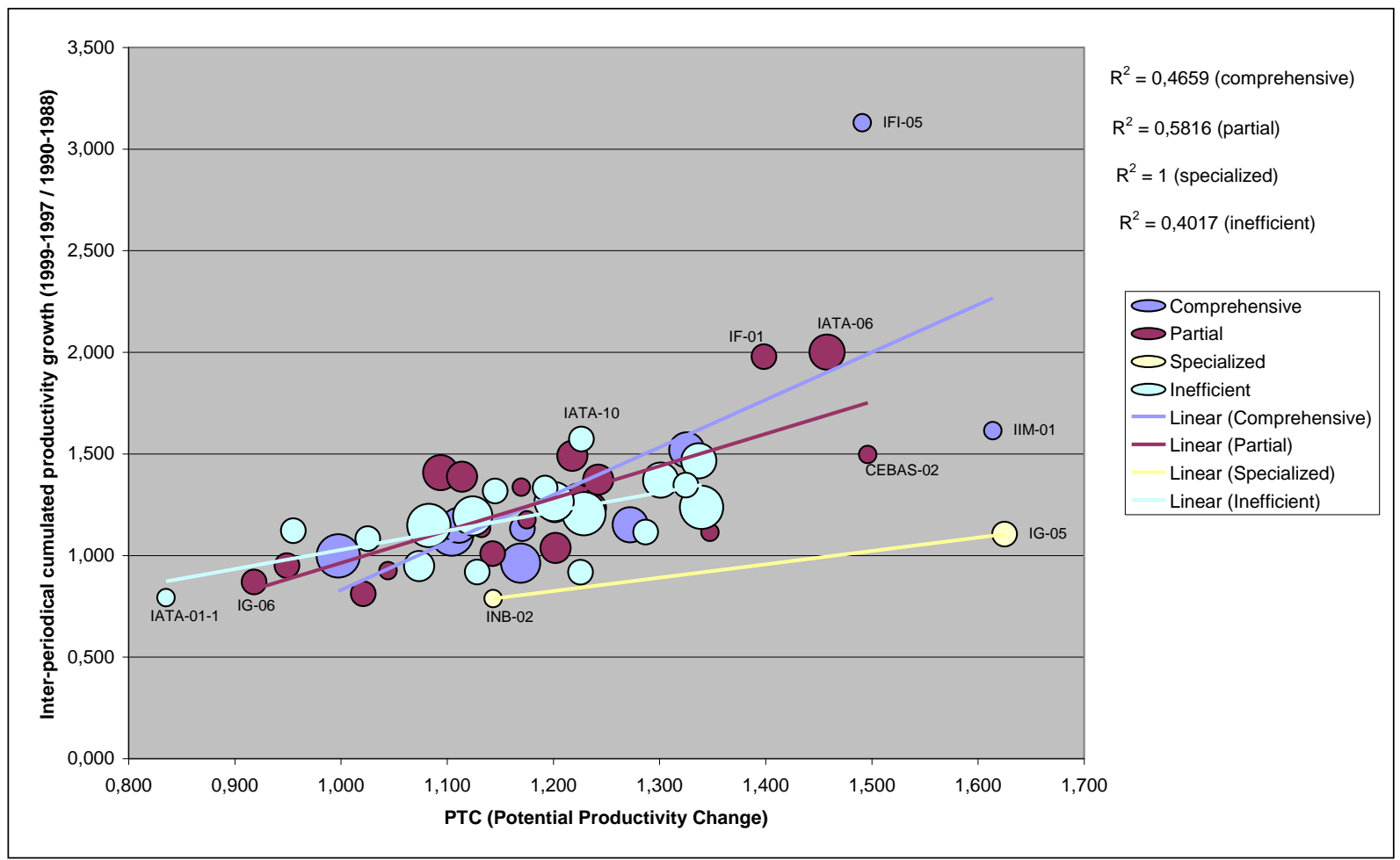


Figure 2.- Distribution of cumulated inter-periodical change in $\hat{\mathrm{M}}_{\mathrm{G}}^{1, t}$ and mean efficiency ${ }^{1}$

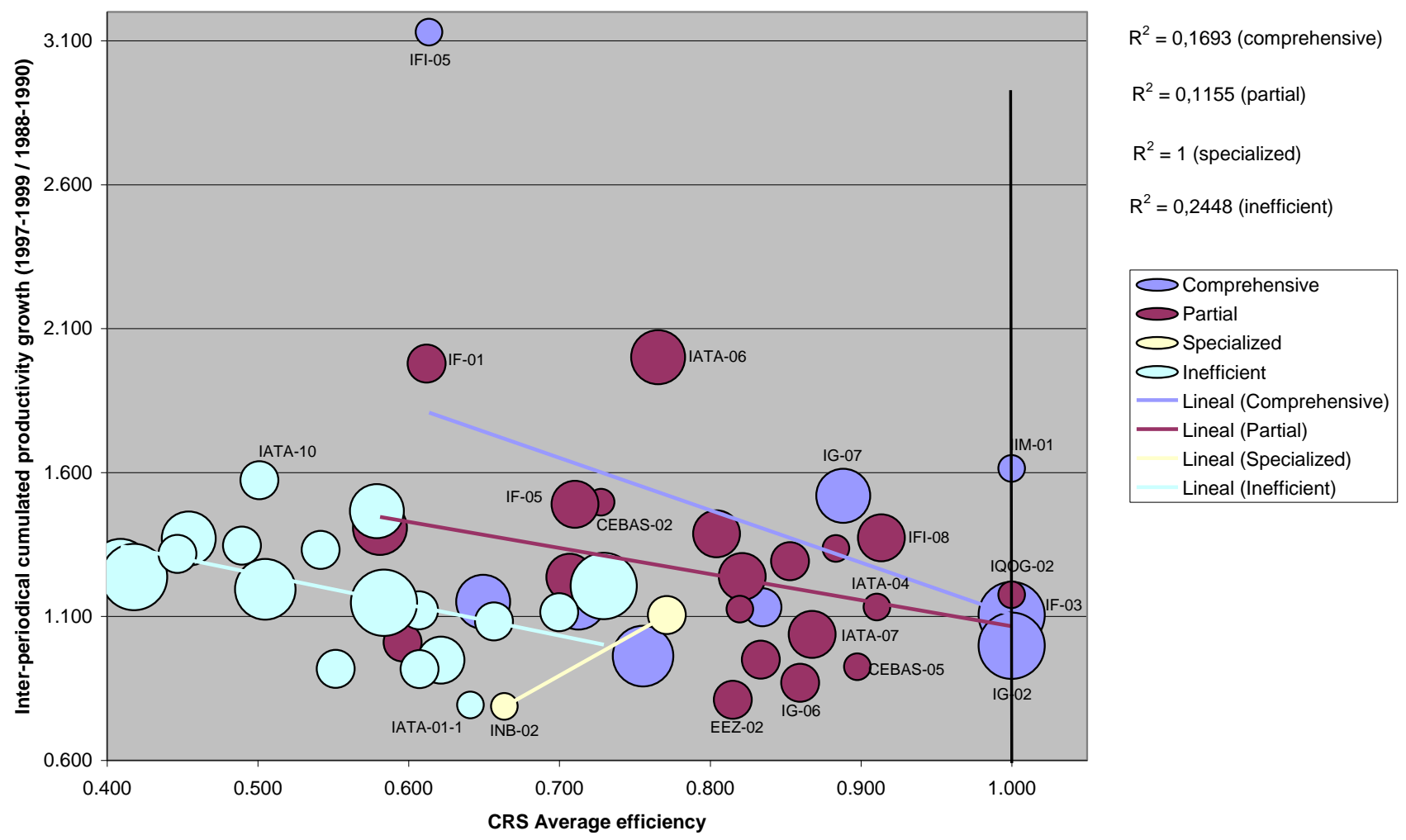

\footnotetext{
${ }^{1}$ The efficiency value is measured as the mean efficiency obtained by the research unit in the periods in which it has participated in the SFTP, while productivity change corresponds to the inter-periodical variation rate reported in Table 2, which as previously discussed also render comparable the values of the units participating in different number of periods. In this sense, the vertical line measures the mean efficiency (measured in constant returns to scale) achieved by all research groups in the four periods (0.691).
} 
Table 1.- Mean values and inter-periodical growth rates for inputs and outputs in the SFTP (\%)

\begin{tabular}{|c|c|c|c|c|c|c|c|}
\hline \multirow[b]{3}{*}{ Mean } & \multirow{2}{*}{\multicolumn{2}{|c|}{ INPUT }} & \multicolumn{5}{|c|}{ OUTPUT } \\
\hline & & & \multicolumn{2}{|c|}{ TRAINING } & \multicolumn{2}{|c|}{ SCIENCE \& TECHNOLOGY } & \multirow{2}{*}{$\frac{\text { SOCIO-ECONOMY }}{\text { Contracts }}$} \\
\hline & Personnel & Public Funding & $\begin{array}{l}\text { Trained } \\
\text { People }\end{array}$ & PhD Theses & $\begin{array}{l}\text { International } \\
\text { Papers }\end{array}$ & $\begin{array}{l}\text { Registered } \\
\text { Patents }\end{array}$ & \\
\hline & FTE & Euro & $\mathrm{N}^{\circ}$ of people & $\mathrm{N}^{\circ}$ of theses & $\mathrm{N}^{\circ}$ of papers & $\mathrm{N}^{\circ}$ of patents & Euro \\
\hline $1988-1990$ & 6.3 & $118,471.1$ & 4.7 & 2.1 & 8.3 & 0.5 & $18,680.9$ \\
\hline $1991-1993$ & 6.0 & $92,198.0$ & 4.6 & 2.2 & 11.0 & 0.2 & $20,607.8$ \\
\hline 1994-1996 & 5.1 & $90,345.9$ & 4.0 & 2.0 & 10.6 & 0.3 & $45,345.4$ \\
\hline 1997-1999 & 4.7 & $108,067.5$ & 6.3 & 1.4 & 11.7 & 0.6 & $49,788.5$ \\
\hline Change rates $(\%)$ & Personnel & Public Funding & $\begin{array}{l}\text { Trained } \\
\text { people }\end{array}$ & $\mathrm{PhD}$ Theses & $\begin{array}{c}\text { International } \\
\text { Papers } \\
\end{array}$ & $\begin{array}{c}\text { Registered } \\
\text { Patents }\end{array}$ & Contracts \\
\hline 1991-93/1988-90 & -3.9 & -22.2 & -1.3 & 2.5 & 32.0 & -56.8 & 10.3 \\
\hline 1994-96/1991-93 & -15.2 & -2.0 & -13.6 & -10.8 & -3.5 & 66.9 & 120.0 \\
\hline 1997-99/1994-96 & -8.2 & 19.6 & 56.3 & -30.5 & 10.2 & 78.6 & 9.8 \\
\hline 1997-99/1988-90 & -25.3 & -8.8 & 33.2 & -36.5 & 40.3 & 28.9 & 166.5 \\
\hline
\end{tabular}


Table 2.- Average inter-periodical cumulated productivity change by groups.

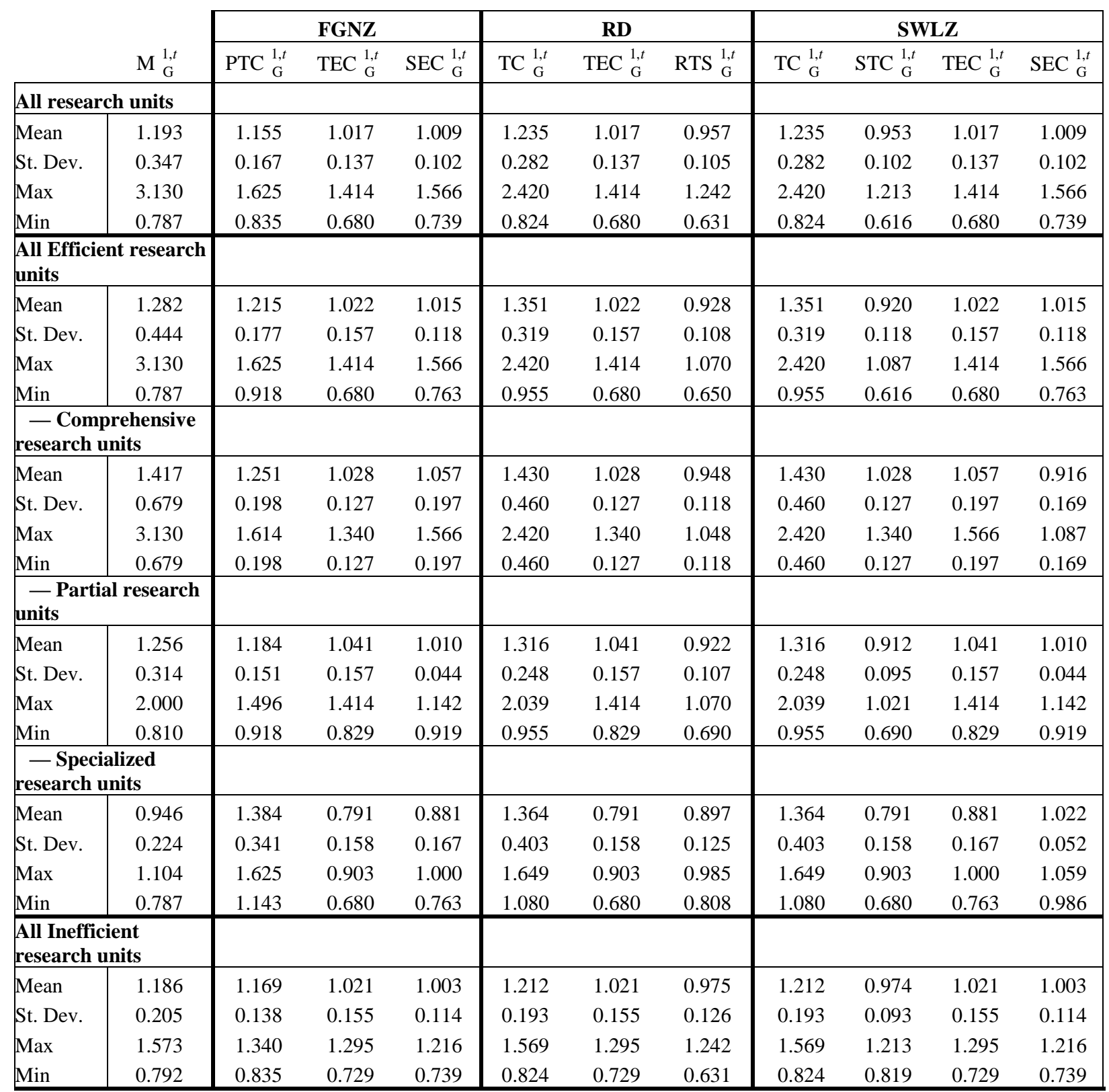

Note: We report mean values for all units classified within the group — see Annex 1 for individual values. 
Table 3.- Distribution of the average inter-periodical cumulated productivity growth.

\begin{tabular}{|c|c|c|c|c|c|c|c|c|c|c|c|}
\hline & \multirow[b]{2}{*}{$\mathrm{M}_{\mathrm{G}}^{1, t}$} & \multicolumn{3}{|c|}{ FGNZ } & \multicolumn{3}{|c|}{ RD } & \multicolumn{4}{|c|}{ SWLZ } \\
\hline & & $\mathrm{PTC}_{\mathrm{G}}^{1, t}$ & TEC ${ }_{\mathrm{G}}^{1, t}$ & $\mathrm{SEC}_{\mathrm{G}}^{1, t}$ & $\mathrm{TC}_{\mathrm{G}}^{1, t}$ & $\mathrm{TEC}_{\mathrm{G}}^{1, t}$ & $\operatorname{RTS}{ }_{\mathrm{G}}^{1, t}$ & $\mathrm{TC}_{\mathrm{G}}^{1, t}$ & $\mathrm{STC}_{\mathrm{G}}^{1, t}$ & $\operatorname{TEC}_{\mathrm{G}}^{1, t}$ & $\mathrm{SEC}_{\mathrm{G}}^{1, t}$ \\
\hline \multicolumn{12}{|c|}{$\mathrm{M}_{\mathrm{G}}^{1, t}>\mathbf{4 0 \%}$; \# research units $=10$} \\
\hline Mean & 1,767 & 1,366 & 1,180 & 1,090 & 1,578 & 1,180 & 0,956 & 1,578 & 1,180 & 1,090 & 0,892 \\
\hline St. Dev. & 0,522 & 0,157 & 0,155 & 0,183 & 0,391 & 0,155 & 0,095 & 0,391 & 0,155 & 0,183 & 0,131 \\
\hline Max & 3,130 & 1,614 & 1,414 & 1,566 & 2,420 & 1,414 & 1,055 & 2,420 & 1,414 & 1,566 & 1,030 \\
\hline \multicolumn{12}{|c|}{$\mathbf{2 0 \%}<\mathrm{M}_{\mathrm{G}}^{1, t}<\mathbf{4 0 \%}$; \# research units $=\mathbf{1 3}$} \\
\hline Mean & 1.302 & 1.225 & 1.063 & 1.011 & 1.316 & 1.063 & 0.949 & 1.316 & 0.937 & 1.063 & 1.011 \\
\hline St. Dev. & 0.061 & 0.067 & 0.093 & 0.111 & 0.133 & 0.093 & 0.144 & 0.133 & 0.079 & 0.093 & 0.111 \\
\hline \multicolumn{12}{|c|}{$\mathbf{0} \%<\mathrm{M}_{\mathrm{G}}^{1, t}<\mathbf{2 0 \%}$; \# research units $=\mathbf{1 6}$} \\
\hline Mean & 1.118 & 1.178 & 0.971 & 0.996 & 1.271 & 0.971 & 0.939 & 1.271 & 0.946 & 0.971 & 0.996 \\
\hline St. Dev. & 0.046 & 0.154 & 0.141 & 0.059 & 0.250 & 0.141 & 0.122 & 0.250 & 0.135 & 0.141 & 0.059 \\
\hline \multicolumn{12}{|c|}{$\mathbf{M}_{\mathrm{G}}^{1, t}<\mathbf{0 \%}$; \# research units $=\mathbf{1 1}$} \\
\hline Mean & 0.898 & 1.046 & 0.902 & 0.961 & 1.075 & 0.902 & 0.938 & 1.075 & 0.977 & 0.902 & 0.961 \\
\hline St. Dev. & 0.072 & 0.117 & 0.091 & 0.076 & 0.120 & 0.091 & 0.101 & 0.120 & 0.085 & 0.091 & 0.076 \\
\hline Min & 0.787 & 0.835 & 0.729 & 0.763 & 0.824 & 0.729 & 0.694 & 0.824 & 0.755 & 0.729 & 0.763 \\
\hline
\end{tabular}


Table 4.- Productivity change between periods by group categories, Eq. (3)

\begin{tabular}{|c|c|c|c|c|c|c|c|c|c|c|c|}
\hline & \multirow[b]{2}{*}{$\mathbf{M}_{\mathrm{G}}^{1, t}$} & \multicolumn{3}{|c|}{ FGNZ } & \multicolumn{3}{|c|}{ RD } & \multicolumn{4}{|c|}{ SWLZ } \\
\hline & & PTC ${ }_{\mathrm{G}}^{1, t}$ & $\operatorname{TEC}_{\mathrm{G}}^{1, t}$ & $\mathrm{SEC}_{\mathrm{G}}^{1, t}$ & $\mathrm{TC}{ }_{\mathrm{G}}^{1, t}$ & $\mathrm{TEC}_{\mathrm{G}}^{1, t}$ & $\mathrm{RTS}_{\mathrm{G}}^{1, t}$ & $\mathrm{TC}_{\mathrm{G}}^{1, t}$ & $\mathrm{STC}_{\mathrm{G}}^{1, t}$ & TEC ${ }_{\mathrm{G}}^{1, t}$ & $\operatorname{SEC}_{\mathrm{G}}^{1, t}$ \\
\hline \multicolumn{12}{|c|}{ All research units } \\
\hline 1988-90/91-93 & 1.809 & 1.496 & 1.115 & 1.023 & 1.596 & 1.115 & 0.993 & 1.596 & 1.019 & 1.115 & 1.023 \\
\hline 1991-93/94-96 & 1.641 & 1.678 & 0.863 & 1.151 & 1.952 & 0.863 & 1.020 & 1.952 & 0.936 & 0.863 & 1.151 \\
\hline 1994-96/97-99 & 1.548 & 1.090 & 1.584 & 0.982 & 1.438 & 1.584 & 0.880 & 1.438 & 0.915 & 1.584 & 0.982 \\
\hline \multicolumn{12}{|c|}{$\begin{array}{l}\text { All Efficient research } \\
\text { units }\end{array}$} \\
\hline 1988-90/91-93 & 1.883 & 1.549 & 1.081 & 1.010 & 1.758 & 1.081 & 0.911 & 1.758 & 0.969 & 1.081 & 1.010 \\
\hline 1991-93/94-96 & 2.043 & 1.812 & 0.951 & 1.177 & 2.153 & 0.951 & 1.026 & 2.153 & 0.921 & 0.951 & 1.177 \\
\hline 1994-96/97-99 & 1.548 & 1.090 & 1.584 & 0.982 & 1.438 & 1.584 & 0.880 & 1.438 & 0.915 & 1.584 & 0.982 \\
\hline \multicolumn{12}{|c|}{$\begin{array}{l}\text { - Comprehensive } \\
\text { research units }\end{array}$} \\
\hline 1988-90/91-93 & 2.803 & 1.755 & 1.151 & 1.189 & 2.287 & 1.151 & 0.962 & 2.287 & 0.887 & 1.151 & 1.189 \\
\hline 1991-93/94-96 & 1.192 & 1.159 & 1.030 & 1.013 & 1.139 & 1.030 & 1.011 & 1.139 & 1.018 & 1.030 & 1.013 \\
\hline 1994-96/97-99 & 0.938 & 1.056 & 0.971 & 0.951 & 1.242 & 0.971 & 0.862 & 1.242 & 0.930 & 0.971 & 0.951 \\
\hline \multicolumn{12}{|c|}{$\begin{array}{l}\text { - Partial research } \\
\text { units }\end{array}$} \\
\hline 1988-90/91-93 & 1.257 & 1.337 & 1.044 & 0.901 & 1.355 & 1.044 & 0.875 & 1.355 & 1.020 & 1.044 & 0.901 \\
\hline 1991-93/94-96 & 2.459 & 2.077 & 0.955 & 1.250 & 2.577 & 0.955 & 1.034 & 2.577 & 0.880 & 0.955 & 1.250 \\
\hline 1994-96/97-99 & 1.710 & 1.055 & 1.465 & 1.013 & 1.434 & 1.465 & 0.954 & 1.434 & 0.942 & 1.465 & 1.013 \\
\hline \multicolumn{12}{|c|}{$\begin{array}{l}\text { - Specialized } \\
\text { research units }\end{array}$} \\
\hline 1988-90/91-93 & 2.662 & 2.662 & 1.000 & 1.000 & 2.765 & 1.000 & 0.963 & 2.765 & 0.963 & 1.000 & 1.000 \\
\hline 1991-93/94-96 & 0.506 & 1.613 & 0.314 & 0.999 & 1.622 & 0.314 & 0.993 & 1.622 & 0.994 & 0.314 & 0.999 \\
\hline 1994-96/97-99 & - & - & - & - & - & - & - & - & - & - & - \\
\hline \multicolumn{12}{|c|}{$\begin{array}{l}\text { Inefficient research } \\
\text { units } \\
\end{array}$} \\
\hline 1988-90/91-93 & 1.646 & 1.381 & 1.190 & 1.050 & 1.240 & 1.190 & 1.176 & 1.240 & 1.129 & 1.190 & 1.050 \\
\hline 1991-93/94-96 & 0.895 & 1.429 & 0.702 & 1.104 & 1.578 & 0.702 & 1.010 & 1.578 & 0.964 & 0.702 & 1.104 \\
\hline 1994-96/97-99 & 1.780 & 1.157 & 2.154 & 0.968 & 1.578 & 2.154 & 0.802 & 1.578 & 0.870 & 2.154 & 0.968 \\
\hline
\end{tabular}

Note: the different indices are based on the first period (1988-90) and the consecutive periods correspond to the following years: $1, t: 1988-90 / 91-93 ; t, t+1: 1991-93 / 94-96$, and $t+1, t+2: 1994-96 / 97-99$ 
Annex 1. Average inter-periodical cumulated productivity change for individual research units.

\begin{tabular}{|c|c|c|c|c|c|c|c|c|c|c|c|}
\hline & \multicolumn{4}{|c|}{ FGNZ } & \multicolumn{3}{|c|}{ RD } & \multicolumn{4}{|c|}{ SWLZ } \\
\hline & $\mathbf{M}_{G}^{1, t}$ & PTC ${ }_{G}^{1, t}$ & $\operatorname{TEC}_{G}^{1, t}$ & $\operatorname{SEC}_{G}^{1, t}$ & $\mathrm{TC}_{G}^{1, t}$ & $\operatorname{TEC}{ }_{G}^{1, t}$ & $\operatorname{RTS}_{G}^{1, t}$ & $\mathrm{TC}_{G}^{1, t}$ & $\operatorname{STC}{ }_{G}^{1, t}$ & $\operatorname{TEC}_{G}^{1, t}$ & $\operatorname{SEC}_{G}^{1,}$ \\
\hline$\overline{\text { CEBAS-01 }}$ & 1.291 & 1.222 & 1.050 & 1.006 & 1.387 & 1.050 & 0.886 & 1.387 & 0.881 & 1.050 & 1.006 \\
\hline CEBAS-02 & 1.496 & 1.496 & 1.000 & 1.000 & 1.517 & 1.000 & 0.986 & 1.517 & 0.986 & 1.000 & 1.000 \\
\hline CEBAS-03 & 1.336 & 1.170 & 1.000 & 1.142 & 1.329 & 1.000 & 1.005 & 1.329 & 0.880 & 1.000 & 1.142 \\
\hline CEBAS-04 & 1.331 & 1.192 & 1.115 & 1.000 & 1.225 & 1.115 & 0.974 & 1.225 & 0.973 & 1.115 & 1.000 \\
\hline CEBAS-05 & 0.924 & 1.044 & 0.890 & 0.995 & 1.057 & 0.890 & 0.983 & 1.057 & 0.988 & 0.890 & 0.995 \\
\hline CID-01 & 1.264 & 1.201 & 0.868 & 1.212 & $\mid 1.171$ & 0.868 & 1.242 & 1.171 & 1.025 & 0.868 & 1.212 \\
\hline EEZ-02 & 0.810 & 1.021 & 0.829 & 0.957 & 1.089 & 0.829 & 0.897 & 1.089 & 0.938 & 0.829 & 0.957 \\
\hline IATA-01 & 1.205 & 1.229 & 1.000 & 0.981 & 1.500 & 1.000 & 0.803 & 1.500 & 0.819 & 1.000 & 0.981 \\
\hline IATA-01-1 & 0.792 & 0.835 & 0.951 & 0.997 & 0.824 & 0.951 & 1.010 & 0.824 & 1.013 & 0.951 & 0.997 \\
\hline IATA-02 & 0.962 & 1.169 & 0.908 & 0.906 & 1.075 & 0.908 & 0.985 & 1.075 & 1.087 & 0.908 & 0.906 \\
\hline IATA-03 & 1.236 & 1.236 & 1.000 & 1.000 & 1.241 & 1.000 & 0.996 & 1.241 & 0.996 & 1.000 & 1.000 \\
\hline IATA-04 & 1.133 & 1.133 & 1.000 & 1.000 & 1.198 & 1.000 & 0.945 & 1.198 & 0.945 & 1.000 & 1.000 \\
\hline IATA-05 & 0.947 & 1.074 & 0.884 & 0.998 & 1.064 & 0.884 & 1.007 & 1.064 & 1.009 & 0.884 & 0.998 \\
\hline IATA-06 & 2.000 & 1.458 & 1.363 & 1.007 & 2.039 & 1.363 & 0.720 & 2.039 & 0.715 & 1.363 & 1.007 \\
\hline IATA-07 & 1.037 & 1.202 & 0.882 & 0.978 & 1.177 & 0.882 & 0.999 & 1.177 & 1.021 & 0.882 & 0.978 \\
\hline IATA-08 & 1.009 & 1.143 & 0.884 & 0.999 & 1.262 & 0.884 & 0.904 & 1.262 & 0.906 & 0.884 & 0.999 \\
\hline IATA-09 & 1.370 & 1.301 & 1.083 & 0.972 & 1.260 & 1.083 & 1.004 & 1.260 & 1.033 & 1.083 & 0.972 \\
\hline IATA-10 & 1.573 & 1.227 & 1.055 & 1.216 & 1.414 & 1.055 & 1.055 & 1.414 & 0.868 & 1.055 & 1.216 \\
\hline IATA-11 & 0.918 & 1.128 & 0.803 & 1.013 & 1.170 & 0.803 & 0.977 & 1.170 & 0.964 & 0.803 & 1.013 \\
\hline IF-01 & 1.978 & 1.398 & 1.414 & 1.000 & \begin{tabular}{|l|l|} 
& 1.497 \\
\end{tabular} & 1.414 & 0.934 & 1.497 & 0.934 & 1.414 & 1.000 \\
\hline IF-02 & 1.113 & 1.348 & 0.832 & 0.992 & 1.553 & 0.832 & 0.861 & 1.553 & 0.868 & 0.832 & 0.992 \\
\hline IF-03 & 1.105 & 1.105 & 1.000 & 1.000 & 1.699 & 1.000 & 0.650 & 1.699 & 0.650 & 1.000 & 1.000 \\
\hline IF-03-1 & 1.000 & 1.000 & 1.000 & 1.000 & 1.000 & 1.000 & 1.000 & 1.000 & 1.000 & 1.000 & 1.000 \\
\hline IF-04 & 1.148 & 1.111 & 1.056 & 0.978 & 1.066 & 1.056 & 1.019 & 1.066 & 1.042 & 1.056 & 0.978 \\
\hline IF-05 & 1.489 & 1.218 & 1.210 & 1.011 & 1.220 & 1.210 & 1.009 & 1.220 & 0.998 & 1.210 & 1.011 \\
\hline IF-06 & 0.917 & 1.226 & 0.729 & 1.026 & 1.262 & 0.729 & 0.996 & 1.262 & 0.971 & 0.729 & 1.026 \\
\hline IF-07 & 1.082 & 1.025 & 1.063 & 0.993 & 1.197 & 1.063 & 0.851 & 1.197 & 0.857 & 1.063 & 0.993 \\
\hline IF-08 & 1.466 & 1.337 & 1.153 & 0.951 & 1.298 & 1.153 & 0.979 & 1.298 & 1.030 & 1.153 & 0.951 \\
\hline IF-09 & 1.121 & 0.955 & 1.162 & 1.009 & 0.933 & 1.162 & 1.033 & 0.933 & 1.024 & 1.162 & 1.009 \\
\hline IFI-01 & 1.407 & 1.094 & 1.216 & 1.057 & 1.212 & 1.216 & 0.955 & 1.212 & 0.903 & 1.216 & 1.057 \\
\hline IFI-02 & 1.147 & 1.083 & 0.948 & 1.117 & 1.105 & 0.948 & 1.095 & 1.105 & 0.980 & 0.948 & 1.117 \\
\hline IQOG-01 & 1.193 & 1.124 & 1.295 & 0.820 & $\mid 0.927$ & 1.295 & 0.994 & 0.927 & 1.213 & 1.295 & 0.820 \\
\hline IFI-03 & 1.236 & 1.340 & 1.249 & 0.739 & 1.569 & 1.249 & 0.631 & 1.569 & 0.854 & 1.249 & 0.739 \\
\hline IFI-05 & 3.130 & 1.491 & 1.340 & 1.566 & 2.420 & 1.340 & 0.965 & 2.420 & 0.616 & 1.340 & 1.566 \\
\hline IFI-08 & 1.373 & 1.242 & 1.100 & 1.005 & 1.474 & 1.100 & 0.847 & 1.474 & 0.843 & 1.100 & 1.005 \\
\hline IG-01 & 1.345 & 1.325 & 1.097 & 0.926 & 1.289 & 1.097 & 0.952 & 1.289 & 1.028 & 1.097 & 0.926 \\
\hline IG-02 & 0.997 & 0.997 & 1.000 & 1.000 & 1.028 & 1.000 & 0.970 & 1.028 & 0.970 & 1.000 & 1.000 \\
\hline IG-03 & 1.131 & 1.171 & 0.967 & 0.999 & 1.188 & 0.967 & 0.985 & 1.188 & 0.986 & 0.967 & 0.999 \\
\hline IG-04 & 1.387 & 1.114 & 1.162 & 1.072 & 1.115 & 1.162 & 1.070 & 1.115 & 0.999 & 1.162 & 1.072 \\
\hline IG-05 & 1.104 & 1.625 & 0.680 & 1.000 & 1.649 & 0.680 & 0.985 & 1.649 & 0.986 & 0.680 & 1.000 \\
\hline IG-06 & 0.869 & 0.918 & 1.030 & 0.919 & 1.216 & 1.030 & 0.694 & 1.216 & 0.755 & 1.030 & 0.919 \\
\hline IG-07 & 1.519 & 1.326 & 1.047 & 1.094 & 1.384 & 1.047 & 1.048 & 1.384 & 0.958 & 1.047 & 1.094 \\
\hline IG-08 & 0.949 & 0.949 & 1.000 & 1.000 & 0.955 & 1.000 & 0.994 & 0.955 & 0.994 & 1.000 & 1.000 \\
\hline IG-09 & 1.150 & 1.273 & 0.934 & 0.968 & 1.236 & 0.934 & 0.996 & 1.236 & 1.030 & 0.934 & 0.968 \\
\hline IG-10 & 1.238 & 1.202 & 1.000 & 1.030 & 1.237 & 1.000 & 1.001 & 1.237 & 0.971 & 1.000 & 1.030 \\
\hline IIM-01 & 1.614 & 1.614 & 1.000 & 1.000 & 1.776 & 1.000 & 0.909 & 1.776 & 0.909 & 1.000 & 1.000 \\
\hline IIM-02 & 1.317 & 1.145 & 1.092 & 1.053 & 1.311 & 1.092 & 0.920 & 1.311 & 0.874 & 1.092 & 1.053 \\
\hline INB-02 & 0.787 & 1.143 & 0.903 & 0.763 & 1.080 & 0.903 & 0.808 & 1.080 & 1.059 & 0.903 & 0.763 \\
\hline INB-04 & 1.114 & 1.287 & 0.836 & 1.036 & 1.298 & 0.836 & 1.027 & 1.298 & 0.991 & 0.836 & 1.036 \\
\hline IPLA-01 & 1.125 & 1.084 & 0.993 & 1.045 & 1.151 & 0.993 & 0.985 & 1.151 & 0.942 & 0.993 & 1.045 \\
\hline IQOG-02 & 1.175 & 1.175 & 1.000 & 1.000 & 1.703 & 1.000 & 0.690 & 1.703 & 0.690 & 1.000 & 1.000 \\
\hline
\end{tabular}




\begin{tabular}{l|l|lll|lll|llll}
\hline Mean & 1.193 & 1.155 & 1.017 & 1.009 & 1.235 & 1.017 & 0.957 & 1.235 & 0.953 & 1.017 & 1.009 \\
St. Dev. & 0.347 & 0.167 & 0.137 & 0.102 & 0.282 & 0.137 & 0.105 & 0.282 & 0.102 & 0.137 & 0.102 \\
Max & 3.130 & 1.625 & 1.414 & 1.566 & 2.420 & 1.414 & 1.242 & 2.420 & 1.213 & 1.414 & 1.566 \\
Min & 0.787 & 0.835 & 0.680 & 0.739 & 0.824 & 0.680 & 0.631 & 0.824 & 0.616 & 0.680 & 0.739 \\
\hline
\end{tabular}

